\title{
Study of Shiny Film Coating on Multi-Fluid Flows of a Rotating Disk Suspended with Nano-Sized Silver and Gold Particles: A Comparative Analysis
}

\author{
Rahmat Ellahi ${ }^{1,2, * \mathbb{D}}$, Ahmed Zeeshan ${ }^{1}\left(\mathbb{D}\right.$, Farooq Hussain ${ }^{1,3}$ and Tehseen Abbas ${ }^{4}$ \\ 1 Department of Mathematics \& Statistics, Faculty of Basic and Applied Sciences (FBAS), International Islamic \\ University (IIUI), Islamabad 44000, Pakistan; ahmad.zeeshan@iiu.edu.pk (A.Z.); \\ farooq.hussain@buitms.edu.pk (F.H.) \\ 2 Department of Mechanical Engineering, University of California Riverside, Riverside, CA 92521, USA \\ 3 Department of Mathematics, Faculty of Arts and Basic Sciences (FABS), Balochistan University of \\ Information Technology, Engineering, and Management Sciences (BUITEMS), Quetta 87300, Pakistan \\ 4 Department of Mathematics, University of Education Lahore, Faisalabad Campus, \\ Faisalabad 38000, Pakistan; tehseen.abbas@ue.edu.pk \\ * Correspondence: rellahi@alumni.ucr.edu
}

Received: 14 September 2018; Accepted: 10 November 2018; Published: 24 November 2018

\begin{abstract}
The current effort is devoted to investigate the shiny thin film with a metallic tactile covering of nanoparticles over the surface of a rotating disk. To decorate, glowing silver and gold particles were chosen. Four illustrative base liquids, namely (i) ethanol, (ii) methanol, (iii) ethylene-glycol, and (iv) water were considered with different geometries, which have great importance in industrial usage. An emphasis on comparative multi nanofluid analysis was used to make a sound judgment on which one of the fluids best suited the metallic glittering process of spin coating. The film thickness process highly depends on the process of evaporation, which takes some time to settle on the disk's surface. It was found that of the base fluids, the best choices were ethanol alloys with silver. Hence, one can conclude that from an experimental point of view, if silver alloy is used for coating, then only those liquids can be considered that exhibit ethanol-like properties. The impact of pertinent parameters with different aspects are graphically illustrated in each case.
\end{abstract}

Keywords: thin film; spin coating; rotating disk; nanoparticles; Newtonian fluids

\section{Introduction}

The mechanical process of covering the surface of an object/substrate with the help of a very thin layer is known as "Coating". This layer can be of some sort of paint, lacquer or a thin polymer sheet, which may be used for protective or decorative purposes. Nowadays, most of the engineered products go through the process of coating to prevent corrosion and to make them attractive [1,2]. From an industrial point of view, coating involves the development of a thin film layer (which can be polymeric or lacquer) on a substrate or fabric etc. If the substrate starts and ends the process wound up in a roll, the process may be termed "roll-to-roll" or "web-based" coating. Apart from a process of simple coating, developing a uniform and thin film or covering to a spinning sample or substrate, is called "spin coating". In the latter sort of coating, a small amount of liquid solution is placed at the center of the highly rotating disk, with the help of a pipette or syringe, resulting in the solution spreading uniformly and evenly in all directions as elaborated in [3]. This is all because of centrifugal forces, which cause liquid solution to spread across the surface uniformly. Application of spin coating is mainly used to fabricate tiny structures, usually of micrometer size or even much smaller, known as the microfabrication process. Manufacturing of solar cells, integrated circuits, insulators, nanomaterials, 
compact disks, magnetic disk coating and microfluidic devices are a few examples of such technology, which depend upon the process of high quality spin coating. The simplicity and relative ease that helps to process any set up is regarded as the main advantage of spin coating. The spinning causes fast airflow around the rotating substrates or disks which results in quick drying of a thin layer of coating. Hence, this saves time and reduces the consumption of energy but a consistent efficiency is also achieved at the scale of nanolength or macroscopic level. Surprisingly, spin coating deals with a process which involves single substrates. This leads to a major drawback of spin coating and puts this on the back foot as compared to the "roll-to-roll" coating process. This disadvantage causes low performance. Also, the fast-drying times mean the actual material usage in a spin coating process is typically very low, around $10 \%$ or less, with the rest being flung off the side and wasted. Despite these drawbacks, spin coating is usually the starting point and benchmark for most academic and industrial processes that require a thin and uniform coating. Moreover, nanofluids can simply be termed as the liquid containing the tiny metallic particles. These tiny particles are invisible to the naked eye, for these range between $1 \mathrm{~nm}$ and $100 \mathrm{~nm}$. In the later phase of the twentieth century, the concept of nanoparticles was introduced by Choi and Eastman [4] as a supporting agent. The initial intention was to obtain immense thermal conductivity of the base fluid. However, Buongiorno $[5,6]$ performed his role focusing on convective heat transfer involving nanoparticles in the concerned base liquids. However, he negated some previous conclusions inferred by different researchers in their investigations. Since then, nanoparticles are being in used in different ways by scientists in their endeavors [7-37]. One cannot deny the beneficial application of nanoparticles from electronics to electrical appliances, from the energy sector to medical sciences working towards the remedy of some fatal disease, it is all mainly due to the blessing of the perfect utility of nanoparticles. Primarily, nanoparticles were meant to enhance the thermal features of a phenomenon involved in it, but recently, nanofluids are being applied in a new dimension, which is in solar collectors. In this application, nanofluids are employed for their tunable optical properties. Consequently, graphene-based nanofluid increases the performance of polymerase chain reaction. As a matter of fact, in some cases nano-technology has improved the performance of spin coating, which requires time to self-assemble or crystallize as the nanoparticles such as gold, silver, zinc oxide, copper and aluminum have significant potential in conductive metal as compared to conventional conductive materials. Especially, incorporating the said nanomaterials into thin films would always pool together electrical and optical properties for multipurpose features that play a key role in fabricating stretchable conductive thin films and coatings, since their mechanical properties include greater flexibility, stretch ability and designed structures. These materials can be easily incorporated into thin films with simple inexpensive solution-based testimony techniques like spin coating, ink-jet printing and spray coating [38,39].

What makes this paper so special is that in this study more than one base fluids suspended with a couple of different nanoparticles have been comparatively studied altogether which, so far, is a novel innovation in the field of applying a thin film of spin coating. To form this shiny silver and gold metallic layer of coating, four different types of base liquids (i.e., water, ethanol, methanol and ethylene-glycol) were brought in to use. It was found that evaporation of the liquid suggested rapidly settling down a shiny metallic layer of silver or gold on the surface of a rotating disk.

\section{Formulation}

Let $V=[\bar{u}(\bar{t}, \bar{r}, \bar{\theta}, \bar{z}) \bar{v}(\bar{t}, \bar{r}, \bar{\theta}, \bar{z}) \bar{w}(\bar{t}, \bar{r}, \bar{\theta}, \bar{z})]$ be the velocity of unsteady, incompressible and viscous multi nanofluids axi-symmetrically rotating disk having an angular velocity $\bar{\Psi}$, as shown in Figure 1 . 


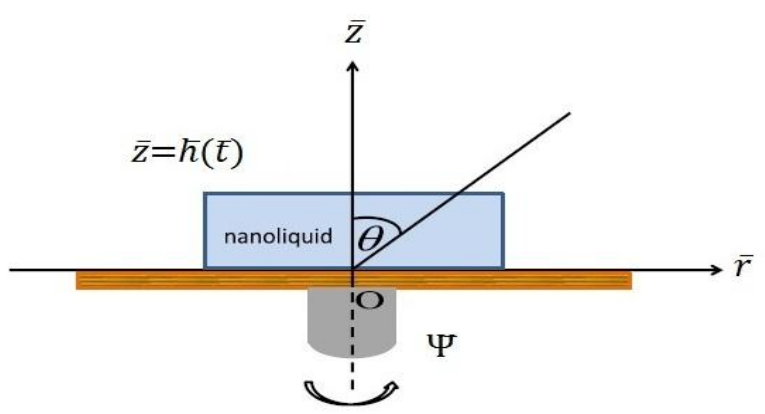

Figure 1. Physical configuration of the rotating disk.

The layer of nanofluid across the surface is evenly spread out; thus, appropriate assumptions can be enlisted as:

i. The nanofluid is assumed to be diluted and an impact of evaporation of a thin layer of the liquid is negligible as the solution is behaving "non-volatile".

ii. The nanoparticles and the base fluid are in equilibrium, therefore, no slip condition is considered.

The governing equations in components form are:

$$
\begin{gathered}
\frac{\partial \bar{u}}{\partial \bar{t}}+\frac{\bar{u}}{\bar{r}}+\frac{\partial \bar{w}}{\partial \bar{z}}=0 \\
\bar{\rho}_{n f}\left(\frac{\partial \bar{u}}{\partial \bar{t}}+\bar{u} \frac{\partial \bar{u}}{\partial \bar{r}}+\bar{w} \frac{\partial \bar{u}}{\partial \bar{z}}-\frac{\bar{v}^{2}}{\bar{r}}\right)=-\frac{\partial \bar{p}}{\partial \bar{r}}+\bar{\mu}_{n f}\left\{\frac{\partial^{2} \bar{u}}{\partial \bar{r}^{2}}+\frac{\partial}{\partial \bar{r}}\left(\frac{\bar{u}}{\bar{r}}\right)+\frac{\partial^{2} \bar{u}}{\partial \bar{z}^{2}}\right\} \\
\bar{\rho}_{n f}\left(\frac{\partial \bar{v}}{\partial \bar{t}}+\bar{u} \frac{\partial \bar{v}}{\partial \bar{r}}+\bar{w} \frac{\partial \bar{v}}{\partial \bar{z}}+\frac{\overline{u v}}{\bar{r}}\right)=-\frac{\partial \bar{p}}{\partial \bar{\theta}}+\bar{\mu}_{n f}\left\{\frac{\partial^{2} \bar{v}}{\partial \bar{r}^{2}}+\frac{\partial}{\partial \bar{r}}\left(\frac{\bar{v}}{\bar{r}}\right)+\frac{\partial^{2} \bar{v}}{\partial \bar{z}^{2}}\right\} \\
\bar{\rho}_{n f}\left(\frac{\partial \bar{w}}{\partial \bar{t}}+\bar{u} \frac{\partial \bar{w}}{\partial \bar{r}}+\bar{w} \frac{\partial \bar{w}}{\partial \bar{z}}\right)=-\frac{\partial \bar{p}}{\partial \bar{z}}+\bar{\mu}_{n f}\left\{\frac{\partial^{2} \bar{w}}{\partial \bar{r}^{2}}+\frac{\bar{w}}{\bar{r}}+\frac{\partial^{2} \bar{w}}{\partial \bar{z}^{2}}\right\} \\
\left(\bar{\rho} C_{p}\right)_{n f}\left(\frac{\partial \bar{T}}{\partial \bar{t}}+\bar{u} \frac{\partial \bar{T}}{\partial \bar{r}}+\bar{w} \frac{\partial \bar{T}}{\partial \bar{z}}\right)=\bar{k}_{n f}\left\{\frac{\partial^{2} \bar{T}}{\partial \bar{r}^{2}}+\frac{1}{\bar{r}} \frac{\partial \bar{T}}{\partial \bar{r}}+\frac{\partial^{2} \bar{T}}{\partial \bar{z}^{2}}\right\}
\end{gathered}
$$

Initial and boundary conditions associated with Equations (1)-(5) are defined in the following sub sections:

\subsection{Initial Conditions}

$$
\left.\begin{array}{l}
\text { (i). } \bar{u}=0, \\
\text { (ii). } \bar{v}=0, \\
\text { (iii). } \bar{w}=0, \\
\text { (iv). } \bar{T}=\bar{T}_{0}, \\
\text { (v). } \bar{h}(\bar{t})=h_{0}
\end{array}\right\} \text {; when } \bar{t}=0
$$

here, $\bar{h}, h_{0}$ and $\bar{T}_{0}$ represent thickness of the film, initial thickness of the film and room temperature respectively. 


\subsection{Boundary Conditions}

- At the surface of the rotating disk

$$
\left.\begin{array}{l}
\text { (i). } \bar{u}=0, \\
\text { (ii). } \bar{v}=\bar{r} \bar{\Psi} \\
(\text { iii). } \bar{w}=0, \\
\bar{T}=\bar{T}_{a}-\frac{\bar{T}_{b}}{2} \bar{r}^{2}
\end{array}\right\} \text {; when } \bar{z}=0
$$

- At the free surface of the rotating disk

$$
\left.\begin{array}{c}
(\mathrm{i}) \cdot \frac{\partial \bar{h}}{\partial \bar{t}}=\bar{w}, \\
\text { (ii). } \bar{p}+2 \bar{\mu}_{n f} \frac{\partial \bar{w}}{\partial \bar{z}}=0, \\
\text { (iii). } \bar{\mu}_{n f}\left(\frac{\partial \bar{u}}{\partial \bar{z}}+\frac{\partial \bar{w}}{\partial \bar{r}}\right)=\frac{\partial \bar{T}}{\partial \bar{r}} \frac{\partial \bar{\sigma}}{\partial \bar{T}^{\prime}}, \\
\text { (iv). } \bar{\mu}_{n f}\left(\frac{\partial \bar{v}}{\partial \bar{z}}\right)=\frac{\partial \bar{T}}{\partial \bar{z}} \frac{\partial \bar{\sigma}}{\partial \bar{T}^{\prime}} \\
\text { (v). } \frac{\partial \bar{T}}{\partial \bar{z}}+L\left(\bar{T}-\bar{T}_{g}\right)=0 .
\end{array}\right\} ; \text { when } \bar{z}=\bar{h}(\bar{t})
$$

where $L$ denotes heat transfer coefficient and $\bar{\sigma}$ stands for surface tension.

By using suitable transformations [40], the governing equations can be obtained as:

$$
\begin{aligned}
& 2 F+\frac{\partial W}{\partial z}=0 \\
& \operatorname{Re} \varnothing_{1}\left(\frac{\partial F}{\partial t}+F^{2}+W \frac{\partial F}{\partial z}\right)=\frac{\partial^{2} F}{\partial z^{2}}+G^{2} \\
& \operatorname{Re} \varnothing_{1}\left(\frac{\partial G}{\partial t}-G \frac{\partial W}{\partial z}+W \frac{\partial G}{\partial z}\right)=\frac{\partial^{2} G}{\partial z^{2}} \\
& \operatorname{RePr} \varnothing_{2}\left(\frac{\partial \Gamma}{\partial t}-\Gamma \frac{\partial W}{\partial z}+W \frac{\partial \Gamma}{\partial z}\right)=\frac{k_{n f}}{k_{f}} \frac{\partial^{2} \Gamma}{\partial z^{2}} \\
& \operatorname{RePr} \varnothing_{2}\left(\frac{\partial \tau}{\partial t}+W \frac{\partial \tau}{\partial z}\right)=\frac{k_{n f}}{k_{f}}\left(\frac{\partial^{2} \tau}{\partial z^{2}}+2 \Gamma\right) \\
& \text { (i). } F(z, t)=0 \text {, } \\
& \text { (ii). } G(z, t)=0 \text {, } \\
& \text { (iii). } W(z, t)=0 \text {, } \\
& \text { (iv). } \Gamma(z, t)=0 \text {, } \\
& \text {; at } t=0 \\
& \text { (v). } \tau(z, t)=0 \text {, } \\
& \text { (vi). } H(t)=1 \text {, } \\
& \text { (i). } F(z, t)=0 \text {, } \\
& \text { (ii). } G(z, t)=1 \text {, } \\
& \text { (iii). } W(z, t)=0 \text {, }\} \text {; at } z=0 \\
& \text { (iv). } \Gamma(z, t)=1 \text {, } \\
& \text { (v). } \tau(z, t)=0 \text {, }
\end{aligned}
$$

here, Re is the Reynolds number and Pr denotes the Prandtl number, whereas $\varnothing_{1}$ and $\varnothing_{2}$ represent dimensionless constants. 
For free surface

$$
\left.\begin{array}{l}
\text { (i). } \frac{\partial F}{\partial z}=\alpha(1-\phi)^{2.5} \Gamma, \\
\quad \text { (ii) } \cdot \frac{\partial G}{\partial z}=0, \\
\text { (iii) } \cdot \frac{\partial \Gamma}{\partial z}=0, \\
\text { (iv). } \frac{\partial \tau}{\partial z}=0, \\
\text { (v). } \frac{d H}{d t}=W .
\end{array}\right\} \text {; at } z=H(t)
$$

\subsection{Thermophysical Properties}

The present investigation is concerned with the development of a thin film of liquid on a rotating disk with different metallic particles that require effective thermo-physical properties of nanofluids and nanoparticles. Two distinctive models proposed by Khanafer and Vafai [41] were chosen to analyze the density and specific heat of the nanofluids; whereas to estimate the thermal conductivity and viscosity of fluids, the thermophysical model [42] is utilized. In view of the thermophysical model in the presence of multi fluids containing two different types of nano-sized metallic particles, the realistic properties were developed as follows:

\subsubsection{For Water as the Base Fluid}

The most significant and highly utilized fluid on this planet is water that contains $997.1 \mathrm{~kg} \cdot \mathrm{m}^{-3}$, density, $0.89 \mathrm{mPa} \cdot \mathrm{S}$. viscosity, $4179 \mathrm{~J} / \mathrm{Kg} \mathrm{m}$ heat capacity and $0.569 \mathrm{~W} \cdot \mathrm{m}^{-1} \cdot \mathrm{K}^{-1}$ thermal conductivity.

- For gold nanoparticles

The mathematical expressions that describe the thermophysical properties of water and gold nanofluids are given as:

$$
\begin{gathered}
\bar{\rho}_{n f}=(1-\phi) \bar{\rho}_{f}-\phi \bar{\rho}_{p} \\
\left(\bar{\rho}_{n f}\right)_{\text {water } / \text { gold }}=997.1(1-\phi)-19300 \phi \\
\bar{\mu}_{n f}=\left(1.013+0.092 \phi-0.015 \phi^{2}\right) \bar{\mu}_{f} \\
\left(\bar{\mu}_{n f}\right)_{\text {water } / \text { gold }}=0.89\left(1.013+0.092 \phi-0.015 \phi^{2}\right) \\
\left(\bar{\rho} C_{P}\right)_{n f}=\left(C_{P}\right)_{f} \bar{\rho}_{f}(1-\phi)-\left(C_{P}\right)_{p} \phi \bar{\rho}_{p} \\
\left(\bar{\rho} C_{P}\right)_{\text {water } / \text { gold }}=(4179)(997.1)(1-\phi)-(126)(19300) \phi \\
\bar{k}_{n f}=(1.0204+0.0249 \phi) \bar{k}_{f} \\
\left(\bar{k}_{n f}\right)_{\text {water/gold }}=0.569(1.0204+0.0249 \phi)
\end{gathered}
$$

where the gold density is $19,300 \mathrm{~kg} \cdot \mathrm{m}^{-3}$ and heat capacity and thermal conductivity are $126 \mathrm{~J} / \mathrm{kg} \mathrm{m}$ and $317 \mathrm{~W} \cdot \mathrm{m}^{-1} \cdot \mathrm{K}^{-1}$, respectively.

- For silver nanoparticles

The thermophysical properties of water and silver nanofluids are given as:

$$
\begin{gathered}
\left(\bar{\rho}_{n f}\right)_{\text {water/silver }}=997.1(1-\phi)-10490 \phi \\
\left(\bar{\mu}_{n f}\right)_{\text {water/silver }}=0.89\left(1.013+0.092 \phi-0.015 \phi^{2}\right) \\
\left(\bar{\rho} C_{P}\right)_{\text {water/silver }}=(4179)(997.1)(1-\phi)-(233)(10490) \phi \\
\left(\bar{k}_{n f}\right)_{\text {water/silver }}=0.569(1.0204+0.0249 \phi)
\end{gathered}
$$


where the density of silver is $10,490 \mathrm{~kg} \cdot \mathrm{m}^{-3}$ while heat capacity and thermal conductivity are respectively $233 \mathrm{~J} / \mathrm{Kg} \mathrm{m}$ and $429 \mathrm{~W} \cdot \mathrm{m}^{-1} \cdot \mathrm{K}^{-1}$

\subsubsection{For Methanol as the Base Fluid}

The features displayed by methanol at room temperature according to the System International (SI) units is of density $790 \mathrm{~kg} \cdot \mathrm{m}^{-3}$ whereas viscosity takes the numerical value $0.543 \mathrm{mPa} \cdot \mathrm{S}$, heat capacity is $2534 \mathrm{~J} / \mathrm{Kg} \mathrm{m}$ and thermal conductivity is $0.201 \mathrm{~W} \cdot \mathrm{m}^{-1} \cdot \mathrm{K}^{-1}$.

- For gold nanoparticles

The mathematical expressions describing the thermophysical properties are given as:

$$
\begin{gathered}
\left(\bar{\rho}_{n f}\right)_{\text {methanol } / \text { gold }}=790(1-\phi)-19300 \phi \\
\left(\bar{\mu}_{n f}\right)_{\text {methanol/gold }}=0.543\left(1.013+0.092 \phi-0.015 \phi^{2}\right) \\
\left(\bar{\rho} C_{P}\right)_{\text {methanol/gold }}=(2543)(790)(1-\phi)-(126)(19300) \phi \\
\left(\bar{k}_{n f}\right)_{\text {methanol } / \text { gold }}=0.201(1.0204+0.0249 \phi)
\end{gathered}
$$

- For silver nanoparticles

For the methanol and silver nanofluids suspension, the physical properties of silver, heat capacity and thermal conductivity are $10,490,790 \mathrm{~kg} \cdot \mathrm{m}^{-3}, 233 \mathrm{~J} / \mathrm{Kg} \mathrm{m}$ and $429 \mathrm{~W} \cdot \mathrm{m}^{-1} \cdot \mathrm{K}^{-1}$ respectively. Thus, thermophysical properties corresponding to this model are:

$$
\begin{gathered}
\left(\bar{\rho}_{n f}\right)_{\text {methanol/silver }}=790(1-\phi)-10490 \phi \\
\left(\bar{\mu}_{n f}\right)_{\text {methanol/silver }}=0.543\left(1.013+0.092 \phi-0.015 \phi^{2}\right) \\
\left(\bar{\rho} C_{P}\right)_{\text {methanol/silver }}=(2543)(790)(1-\phi)-(233)(10490) \phi \\
\left(\bar{k}_{n f}\right)_{\text {methanol/silver }}=0.201(1.0204+0.0249 \phi)
\end{gathered}
$$

In order to make a methanol and gold nanofluids suspension, gold density is $19,300 \mathrm{~kg} \cdot \mathrm{m}^{-3}$. The heat capacity and thermal conductivities are $126 \mathrm{~J} / \mathrm{Kg} \mathrm{m}$ and $317 \mathrm{~W} \cdot \mathrm{m}^{-1} \cdot \mathrm{K}^{-1}$ respectively.

\subsubsection{For Ethanol as the Base Fluid}

The features displayed by ethanol at room temperature have a density of $789 \mathrm{~kg} \cdot \mathrm{m}^{-3}$. The viscosity is $1.074 \mathrm{mPa} \cdot \mathrm{S}$, heat capacity is $2500 \mathrm{~J} / \mathrm{Kg} \mathrm{m}$ and thermal conductivity is $0.0235 \mathrm{~W} \cdot \mathrm{m}^{-1} \cdot \mathrm{K}^{-1}$.

- For gold nanoparticles

For an ethanol and gold nanofluids suspension, the density of gold is $19,300 \mathrm{~kg} \cdot \mathrm{m}^{-3}$, and heat capacity and thermal conductivity are $126 \mathrm{~J} / \mathrm{Kg} \mathrm{m}$ and $317 \mathrm{~W} \cdot \mathrm{m}^{-1} \cdot \mathrm{K}^{-1}$, respectively. Mathematically, it can be written as:

$$
\begin{gathered}
\left(\bar{\rho}_{n f}\right)_{\text {ethanol } / \text { gold }}=789(1-\phi)-19300 \phi \\
\left(\bar{\mu}_{n f}\right)_{\text {ethanol/gold }}=1.074\left(1.013+0.092 \phi-0.015 \phi^{2}\right) \\
\left(\bar{\rho} C_{P}\right)_{\text {ethanol/gold }}=(2500)(789)(1-\phi)-(126)(19300) \phi \\
\left(\bar{k}_{n f}\right)_{\text {ethanol/gold }}=0.0235(1.0204+0.0249 \phi)
\end{gathered}
$$


- For silver nanoparticles

To make an ethanol and silver nanofluids suspension, the density of silver is $10,490 \mathrm{~kg} \cdot \mathrm{m}^{-3}$, heat capacity is $233 \mathrm{~J} / \mathrm{Kg} \mathrm{m}$ and thermal conductivity is $429 \mathrm{~W} \cdot \mathrm{m}^{-1} \cdot \mathrm{K}^{-1}$. The mathematical expressions can be written as:

$$
\begin{gathered}
\left(\bar{\rho}_{n f}\right)_{\text {ethanol/silver }}=789(1-\phi)-10490 \phi \\
\left(\bar{\mu}_{n f}\right)_{\text {ethanol/silver }}=1.074\left(1.013+0.092 \phi-0.015 \phi^{2}\right) \\
\left(\bar{\rho} C_{P}\right)_{\text {ethanol/silver }}=(2500)(789)(1-\phi)-(233)(10490) \phi \\
\left(\bar{k}_{n f}\right)_{\text {ethanol/silver }}=0.0235(1.0204+0.0249 \phi)
\end{gathered}
$$

\subsubsection{For Ethylene-Glycol as the Base Fluid}

The density of ethylene-glycol at room temperature by System International (SI) units system is $1101 \mathrm{~kg} \cdot \mathrm{m}^{-3}$. The viscosity takes the numerical value $0.0162 \mathrm{mPa} \cdot \mathrm{S}$, heat capacity and thermal conductivity are respectively $2400 \mathrm{~J} / \mathrm{Kg} \mathrm{m}$ and $0.256 \mathrm{~W} \cdot \mathrm{m}^{-1} \cdot \mathrm{K}^{-1}$.

- For gold nanoparticles

For an Ethylene-glycol and Gold nanofluids suspension, the physical property of gold density is $19,300 \mathrm{~kg} \cdot \mathrm{m}^{-3}$, heat capacity is $126 \mathrm{~J} / \mathrm{Kg} \mathrm{m}$ and thermal conductivity is $317 \mathrm{~W} \cdot \mathrm{m}^{-1} \cdot \mathrm{K}^{-1}$. Accordingly, the mathematical expression can be written as:

$$
\begin{gathered}
\left(\bar{\rho}_{n f}\right)_{\text {ethylene/gold }}=1101(1-\phi)-19300 \phi \\
\left(\bar{\mu}_{n f}\right)_{\text {ethylene/gold }}=0.0162\left(1.013+0.092 \phi-0.015 \phi^{2}\right) \\
\left(\bar{\rho} C_{P}\right)_{\text {ethylene/gold }}=(2400)(1101)(1-\phi)-(126)(19300) \phi \\
\left(\bar{k}_{n f}\right)_{\text {ethylene/gold }}=0.256(1.0204+0.0249 \phi)
\end{gathered}
$$

- For silver nanoparticles

For the suspension of ethylene-glycol and silver nanofluids the physical property of silver density is $10,490 \mathrm{~kg} \cdot \mathrm{m}^{-3}$. The heat capacity and thermal conductivity are $233 \mathrm{~J} / \mathrm{Kg} \mathrm{m}$ and $429 \mathrm{~W} \cdot \mathrm{m}^{-1} \cdot \mathrm{K}^{-1}$, respectively. On the previous contrast, mathematical expression can be attained as:

$$
\begin{gathered}
\left(\bar{\rho}_{n f}\right)_{\text {ethylene/silver }}=1101(1-\phi)-10490 \phi \\
\left(\bar{\mu}_{n f}\right)_{\text {ethylene/silver }}=0.0162\left(1.013+0.092 \phi-0.015 \phi^{2}\right) \\
\left(\bar{\rho} C_{P}\right)_{\text {ethylene/silver }}=(2400)(1101)(1-\phi)-(233)(10490) \phi \\
\left(\bar{k}_{n f}\right)_{\text {ethylene/silver }}=0.256(1.0204+0.0249 \phi)
\end{gathered}
$$

For the best understating of readers, the realistic physical properties of base fluids and nanoparticles are offered in Tables 1 and 2. 
Table 1. Thermo-physical properties of the base fluids.

\begin{tabular}{|c|c|c|c|c|}
\hline Base Fluids & $\begin{array}{c}\text { Density } \\
\rho\left(\mathrm{kg} \cdot \mathrm{m}^{-3}\right)\end{array}$ & $\begin{array}{l}\text { Viscosity } \\
\mu(\mathrm{mPa} \cdot \mathrm{S})\end{array}$ & $\begin{array}{c}\text { Heat Capacity } \\
C_{p}\left(\mathrm{~J} \cdot \mathrm{kg}^{-1} \cdot \mathrm{K}^{-1}\right)\end{array}$ & $\begin{array}{c}\text { Thermal Conductivity } \\
k\left(\mathrm{~W} \cdot \mathrm{m}^{-1} \cdot \mathrm{K}^{-1}\right)\end{array}$ \\
\hline Water [43] $\left(\mathrm{H}_{2} \mathrm{O}\right)$ & 997 & 0.89 & 4179 & 0.569 \\
\hline Ethanol [44] $\left(\mathrm{C}_{2} \mathrm{H}_{6} \mathrm{O}\right)$ & 789 & 1.074 & 2500 & 0.0235 \\
\hline Methanol [45] $\left(\mathrm{CH}_{4} \mathrm{O}\right)$ & 790 & 0.543 & 2534 & 0.200 \\
\hline Ethylene-Glycol [46] $\left(\mathrm{C}_{2} \mathrm{H}_{6} \mathrm{O}_{2}\right)$ & 1101 & 0.0162 & 2400 & 0.256 \\
\hline
\end{tabular}

Table 2. Physical properties of the nanoparticles.

\begin{tabular}{|c|c|c|c|}
\hline Nano Particles & $\begin{array}{c}\text { Density } \\
\rho\left(\mathrm{kg} \cdot \mathrm{m}^{-3}\right)\end{array}$ & $\begin{array}{c}\text { Heat Capacity } \\
C_{p}\left(\mathrm{~J} \cdot \mathrm{kg}^{-1} \cdot \mathrm{K}^{-1}\right)\end{array}$ & $\begin{array}{l}\text { Thermal Conductivity } \\
k\left(\mathrm{~W} \cdot \mathrm{m}^{-1} \cdot \mathrm{K}^{-1}\right)\end{array}$ \\
\hline Gold [47] (Au) & 19300 & 126 & 317 \\
\hline Silver [48] (Ag) & 10490 & 233 & 429 \\
\hline
\end{tabular}

\section{Analytical Results}

Analytical solutions of nonlinear and coupled Equations (9)-(13) subject to (14)-(16) are obtained as:

$$
\begin{aligned}
& F(z, t)=f_{1}(t) z+f_{2}(t) z^{2}+f_{3}(t) z^{3}+f_{4}(t) z^{4}+f_{5}(t) z^{5}+f_{6}(t) z^{6}+f_{7}(t) z^{7}+f_{8}(t) z^{8} \\
& +f_{9}(t) z^{9}+f_{10}(t) z^{10}+f_{11}(t) z^{11}+f_{12}(t) z^{12}+f_{13}(t) z^{13}+f_{14}(t) z^{14} \\
& +f_{15}(t) z^{15} \\
& G(z, t)=1+g_{1}(t) z+g_{2}(t) z^{2}+g_{3}(t) z^{3}+g_{4}(t) z^{4}+g_{5}(t) z^{5}+g_{6}(t) z^{6}+g_{7}(t) z^{7} \\
& +g_{8}(t) z^{8}+g_{9}(t) z^{9} \\
& W(z, t)=w_{1}(t) z \quad+w_{2}(t) z^{2}+w_{3}(t) z^{3}+w_{4}(t) z^{4}+w_{5}(t) z^{5}+w_{6}(t) z^{6}+w_{7}(t) z^{7}+w_{8}(t) z^{8} \\
& +w_{9}(t) z^{9}+w_{10}(t) z^{10}+w_{11}(t) z^{11}+w_{12}(t) z^{12} \\
& +w_{13}(t) z^{13}+w_{14}(t) z^{14}+w_{15}(t) z^{15}+w_{16}(t) z^{16} \\
& \Gamma(z, t)=1+m_{1}(t) z+m_{2}(t) z^{2}+m_{3}(t) z^{3}+m_{4}(t) z^{4}+m_{5}(t) z^{5}+m_{6}(t) z^{6}+m_{7}(t) z^{7} \\
& +m_{8}(t) z^{8} \\
& \tau(z, t)=n_{1}(t) z \quad+n_{2}(t) z^{2}+n_{3}(t) z^{3}+n_{4}(t) z^{4}+n_{5}(t) z^{5}+n_{6}(t) z^{6}+n_{7}(t) z^{7} \\
& +n_{8}(t) z^{8}+n_{9}(t) z^{9}+n_{10}(t) z^{10}
\end{aligned}
$$

where the expressions $f_{1}, f_{2} \ldots f_{15}, g_{1}, g_{2} \ldots g_{9}, m_{1}, m_{2} \ldots m_{8}, n_{1}, n_{2} \ldots n_{10}$ and $w_{1}, w_{2} \ldots w_{16}$ are given in the Appendix A.

\section{Discussion}

The process of coating heavily depends upon the time taken by any fluid to settle down on the surface of the material; a fluid can only be considered more suitable for the coating if it takes less time to leave its effects on the surface. Moreover, the engaged nanoparticles are of very small size and of a concentration of at most $2 \%$. The effects on viscosity, thermal conductivity, density and heat capacity are evaluated experimentally in many communications. It is now a well-established fact that in the presence of such a small quantity of nanosized particles, the nature of fluid does not change but changes in physical properties are evident. For that, many correlations are presented for different situations and particles. To serve the purpose of this study, four different kinds of Newtonian fluids having diverse physical and chemical properties are considered instead of non-Newtonian fluids because coatings with such types of fluids would have a tremendous impact on the cost, volume, weight, and mechanical properties of electronic, optoelectronic, and photovoltaic devices; thus, this portion is dedicated to the parametric study of the proposed model in which four kinds of Newtonian fluids, such as water, ethanol, methanol and ethylene-glycol are opted for as the base fluids. The gold and silver nanoparticles are used to furnish the thin metallic and shiny coating on the surface of the 
rotating disk. The main reason to carry out this graphical work is to confirm whether or not the obtained mathematical results are in complete coherence with the physical expectation of the spin coatings. Moreover, the graphic illustrations will help to make a sound judgement about the role and contribution of field variables. Major parameters which have been comprehensively focused on are the concentration of the metallic particles and the thermocapillary parameter. Furthermore, the presented parametric study unlike the customary results and discussion have been delicately divided into three following sub sections to make this comparative analysis more clear and fathomable.

\subsection{Thickness of the Film}

The key emphasis in this article is on furnishing a shiny metallic layer of nanoparticles, suspended with different base fluids displaying distinct physical and chemical features altogether. Here, the sole aim is to decide which one of the base fluids is the best suitable choice for this metallic covering over the disk with spin coatings that can quickly spread on the disk in a short span of time. As shown in Figure 2, it can clearly be seen that ethanol is the sole liquid which shows a rapid action with both metals as compared to the other base fluids. It is in accordance with their physical prospects, due to their densities, which help them evaporate quickly and results in a shiny metallic nanoliquids coating on the disk. On the other hand, silver particles' coating is much faster than gold, as Figure 3 shows.

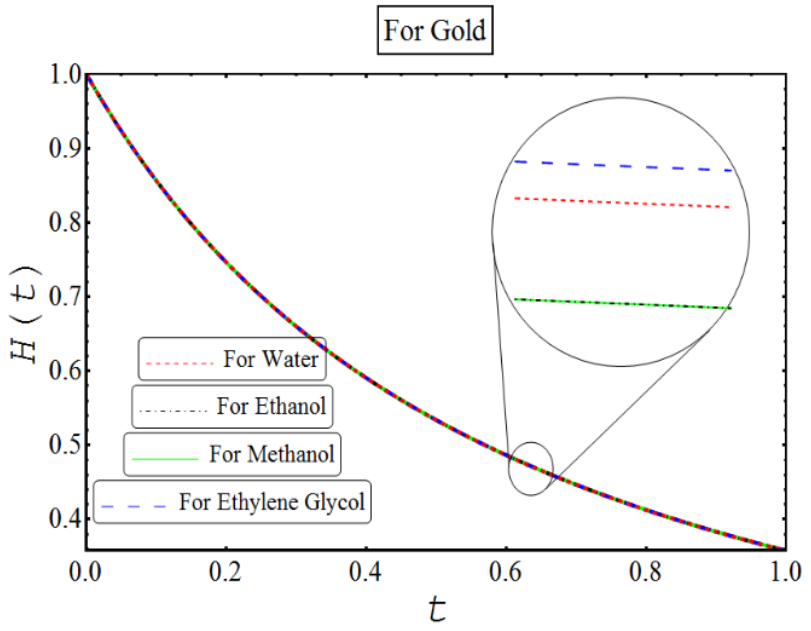

Figure 2. Behaviour of film thickness for different base fluids containing gold nanoparticles.

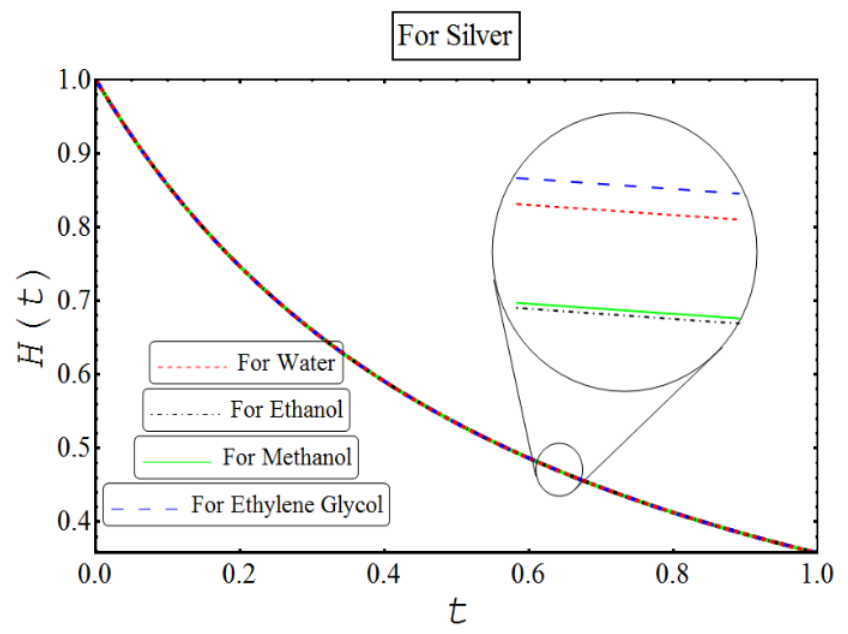

Figure 3. Behaviour of film thickness for different base fluids containing silver particles 
In Figures 4-7, thermocapillary parameters and the concentration of the metallic particles' influence on nanofluid coating have been displayed. It is a well-recognized fact that the thicker solution yields to the thicker layer of the film. The thermocapillary parameter depletes and attenuates this metallic layer as shown in Figures 4 and 5. From the above given facts, it is inferred that ethanol and silver particles share a great deal of mutual compatibility. Thickness of the film increases in size upon the additional supply of metallic particles as shown in Figures 6 and 7. This confirms the above preceding claim that an increase of the particles will enlarge the film thickness in size. Therefore, it can be concluded that any fluids and particles which exhibit different characteristics like ethanol and silver are regarded as the most suitable option for this metallic process of coating. Consequently, to see the effects of thermal, radial and azimuthal velocity, ethanol was chosen as a base fluid.

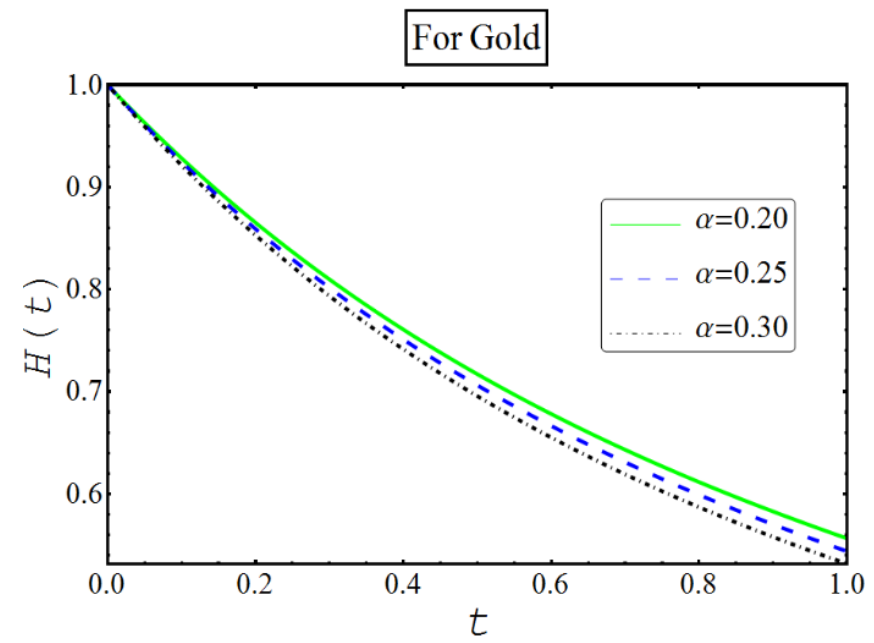

Figure 4. Behaviour of film thickness for thermocapillary parameter for gold particles.

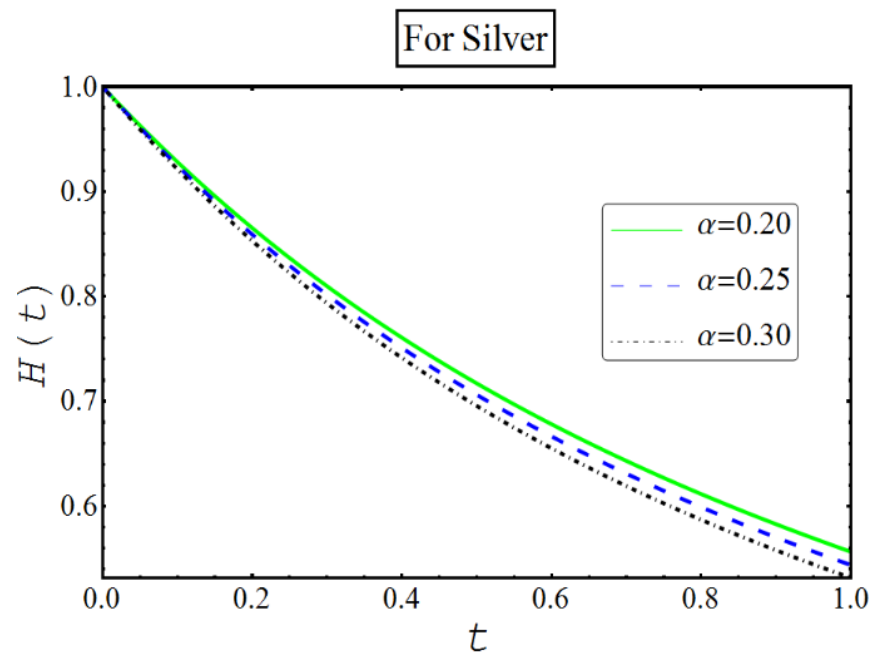

Figure 5. Behaviour of film thickness for thermocapillary for silver particles parameter. 


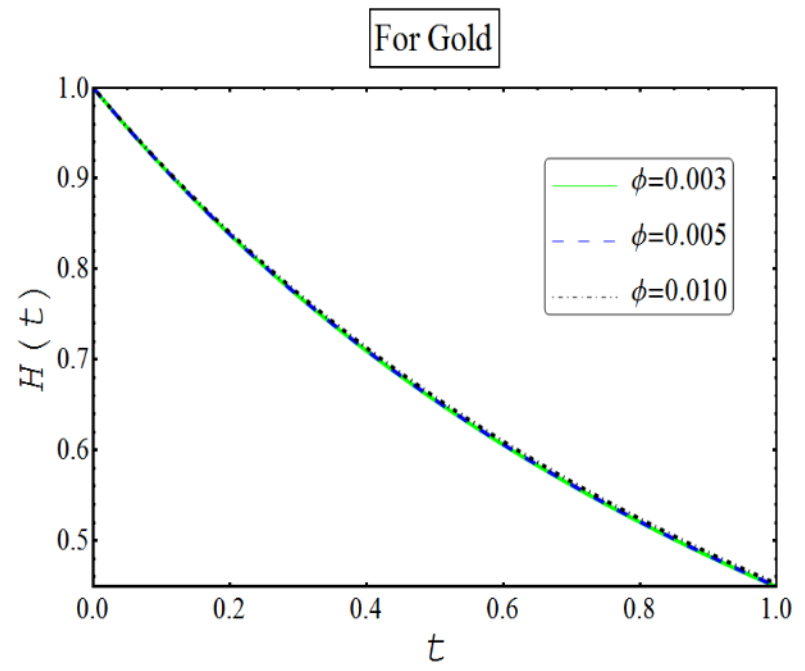

Figure 6. Effects of the concentration of particles on film thickness for the case of gold.

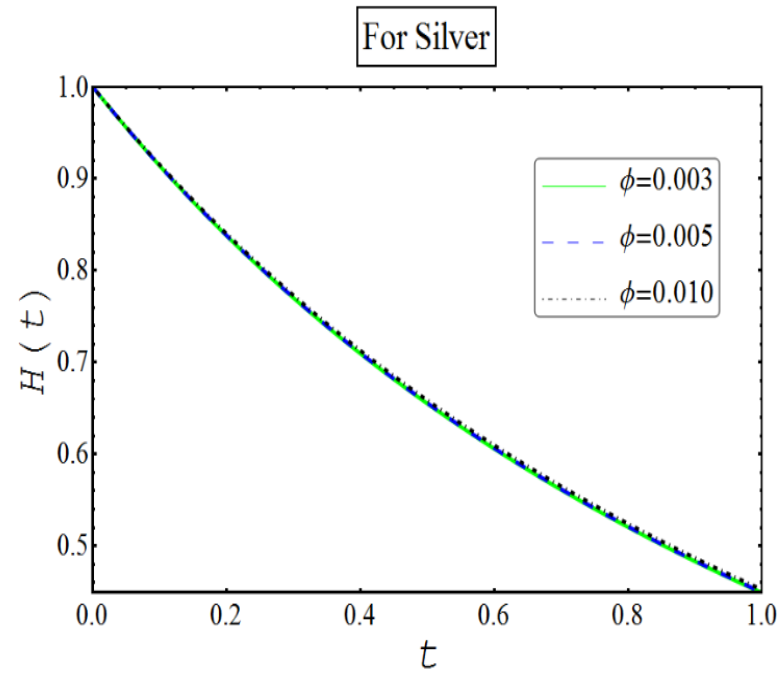

Figure 7. Effects of the concentration of particles on film thickness for the case of silver.

\subsection{Radial Velocity and Azimuthal Velocity}

In Figures 8-21, the radial and azimuthal velocities have been sketched for all base fluids, the thermocapillary parameter and the concentration of the particles. In view of suitable transformation, the mathematical expressions take the following final form:

$$
\begin{aligned}
& U(z, t)=R F(z, t) \\
& V(z, t)=R G(z, t)
\end{aligned}
$$




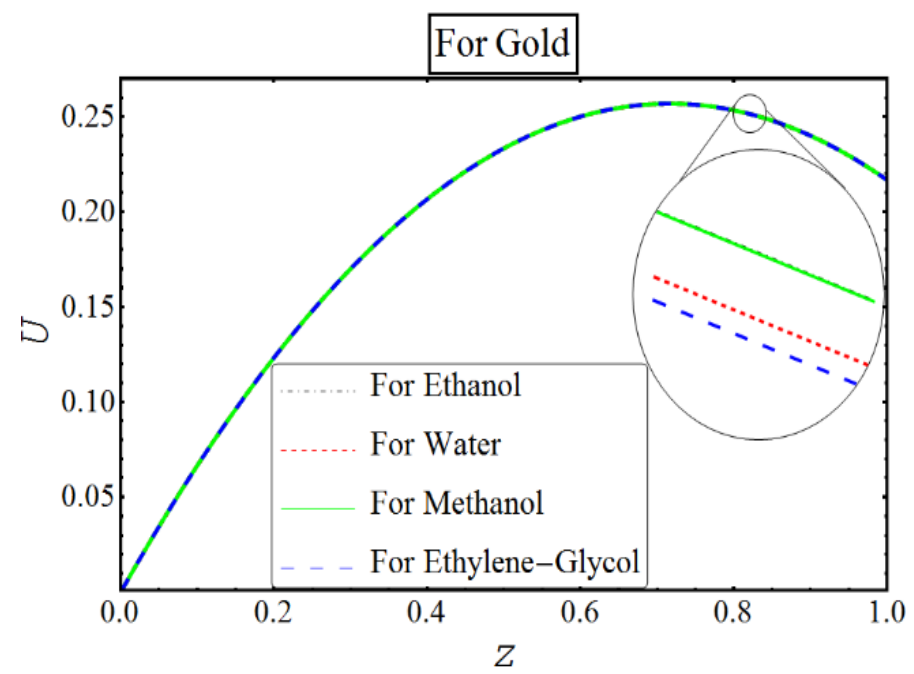

Figure 8. Behavior of radial velocity for each fluid comprising gold particles.

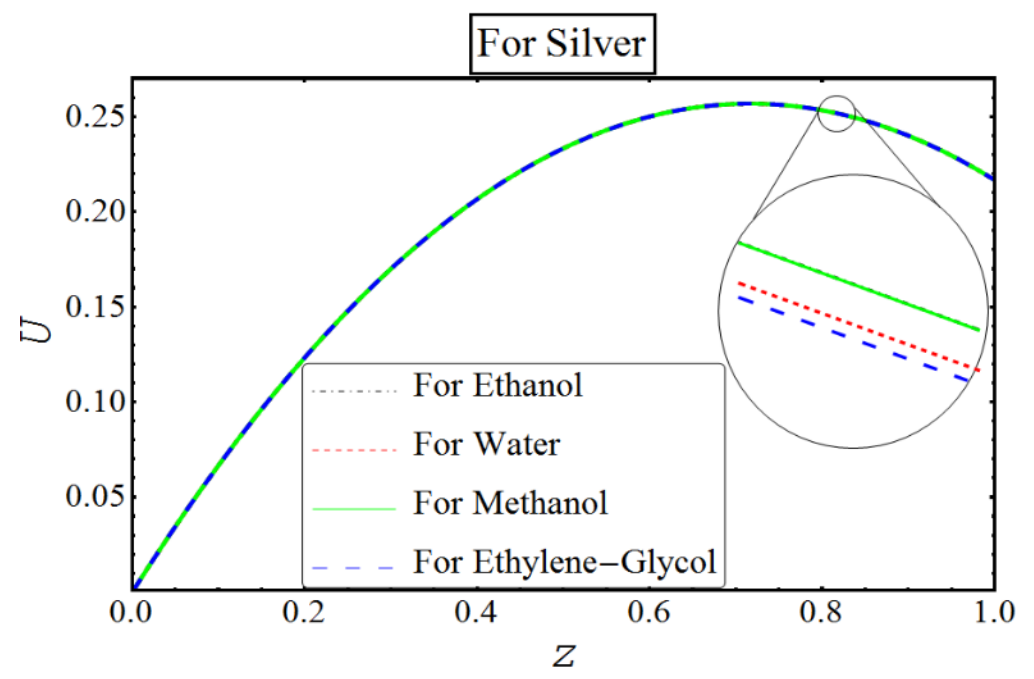

Figure 9. Behavior of radial velocity for each fluid comprising silver particles.

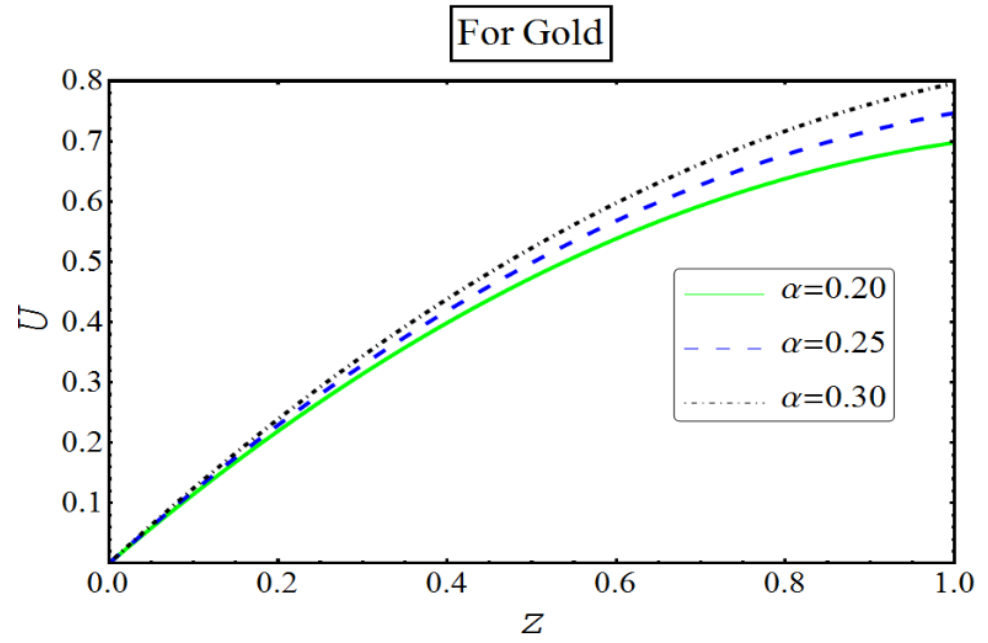

Figure 10. Behavior of radial velocity for the thermocapillary parameter comprising gold particles. 


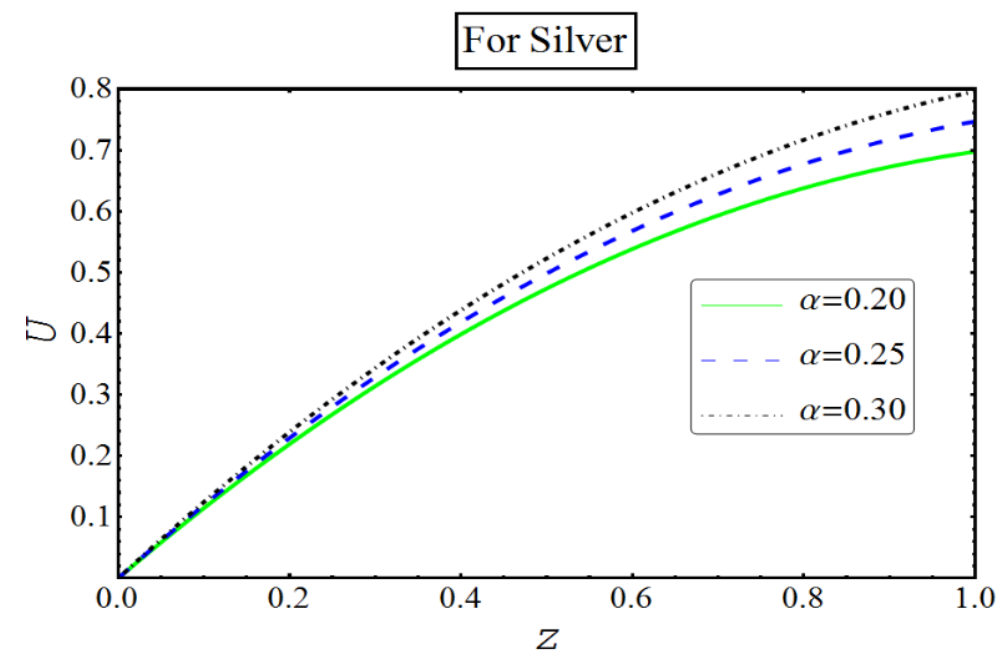

Figure 11. Behavior of radial velocity for the thermocapillary parameter comprising gold particles.

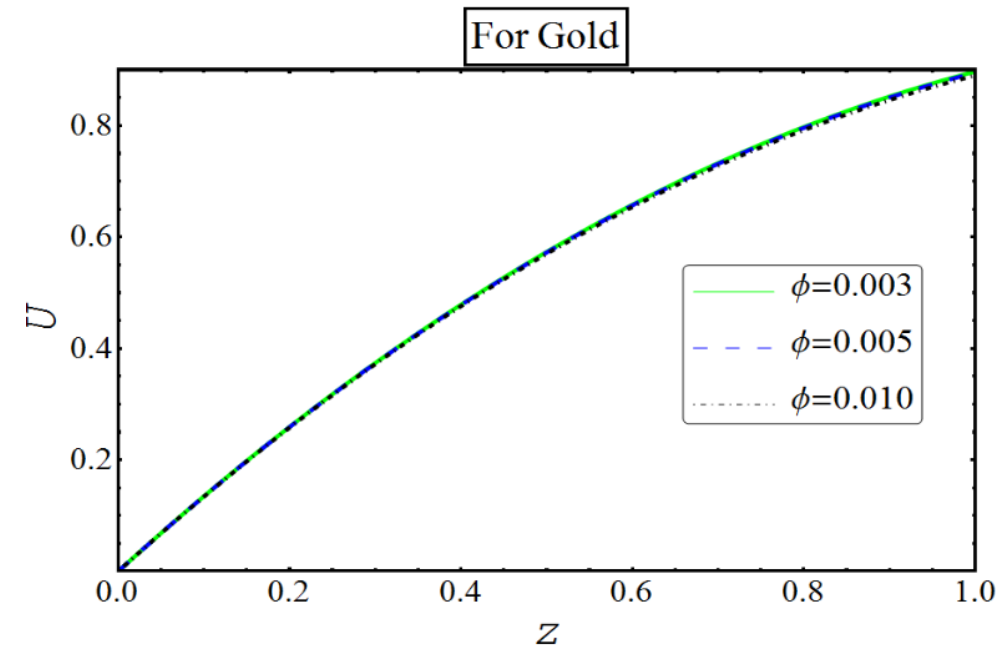

Figure 12. Effects of concentration particles on radial velocity with gold particles.

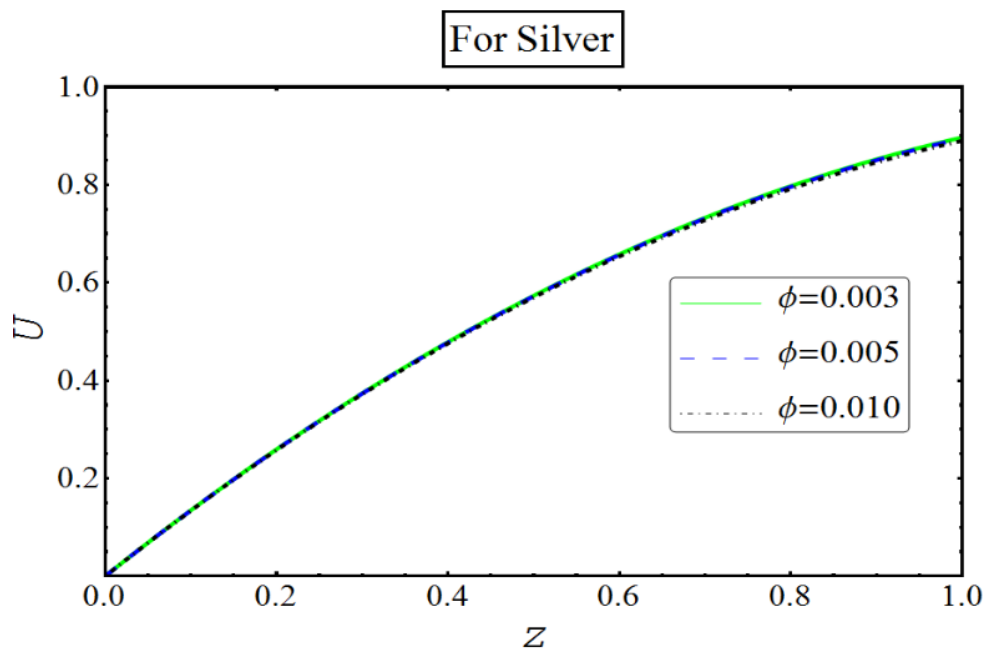

Figure 13. Effects of concentration particles on radial velocity with silver particles. 


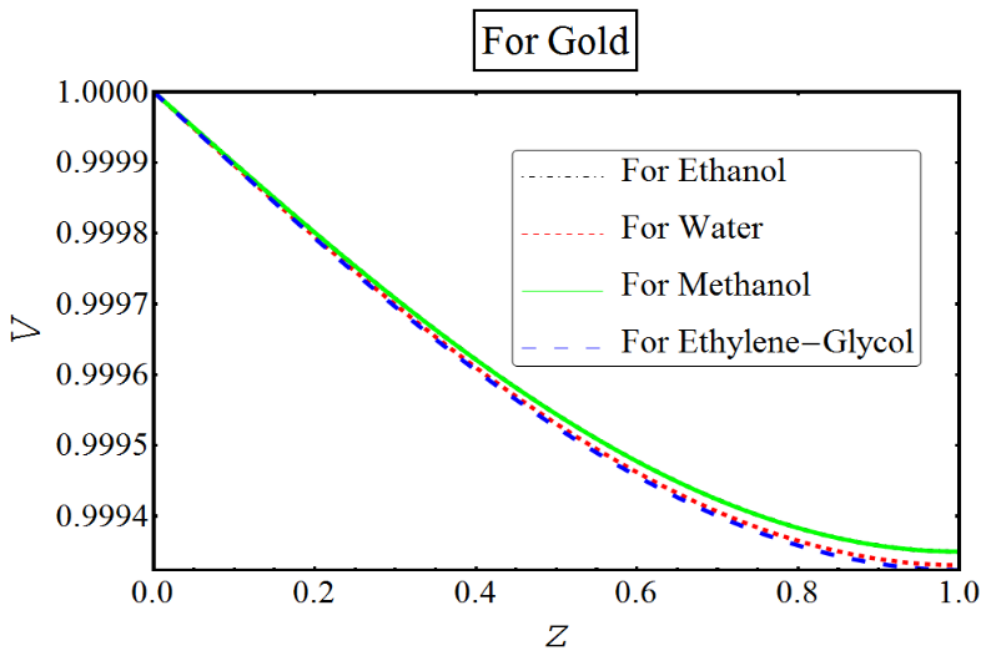

Figure 14. Behavior of azimuthal velocity for each fluid with gold particles.

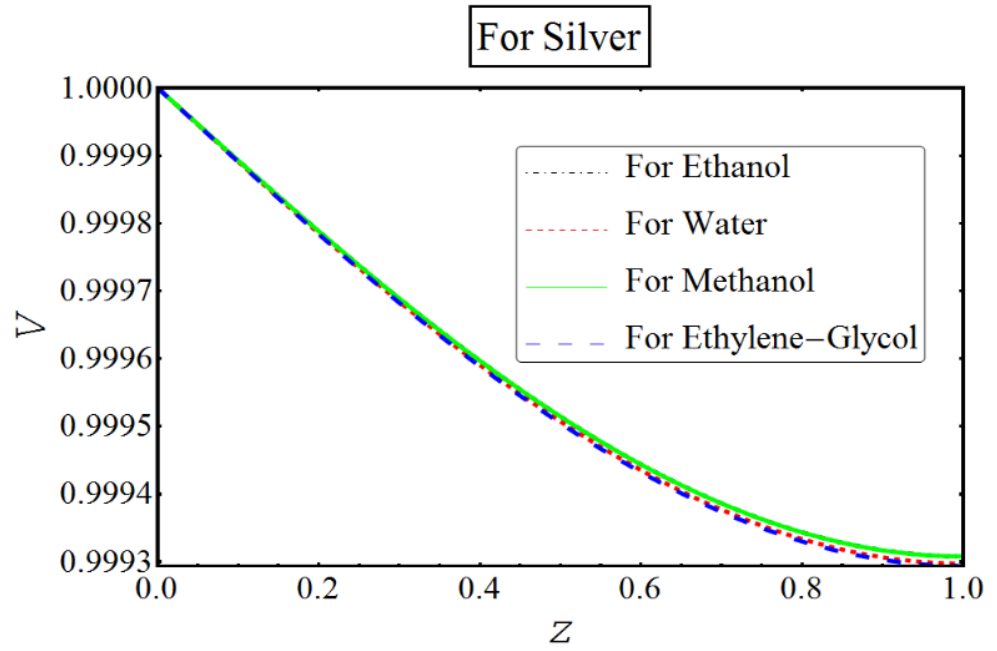

Figure 15. Behavior of azimuthal velocity for each fluid with silver particles.

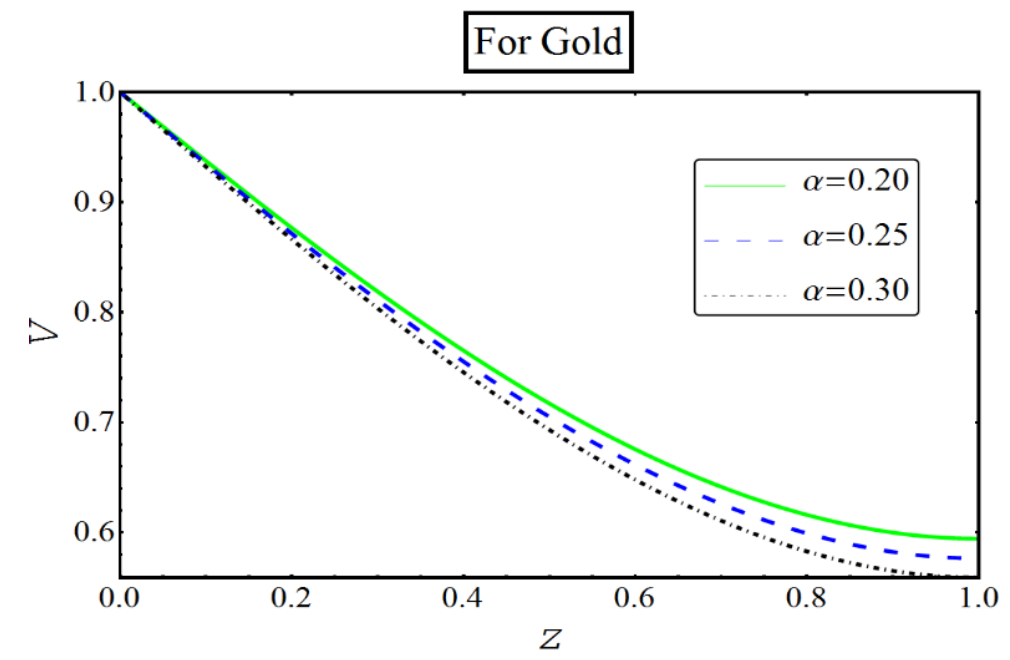

Figure 16. Behavior of azimuthal velocity for the thermocapillary parameter with gold particles. 


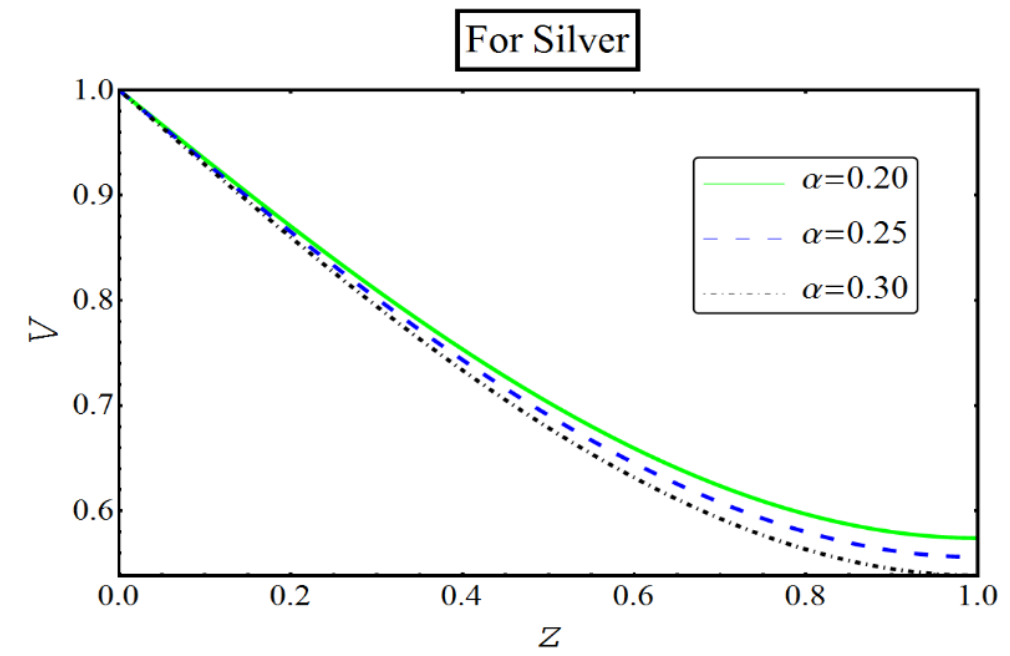

Figure 17. Behavior of azimuthal velocity for the thermocapillary parameter with silver particles.

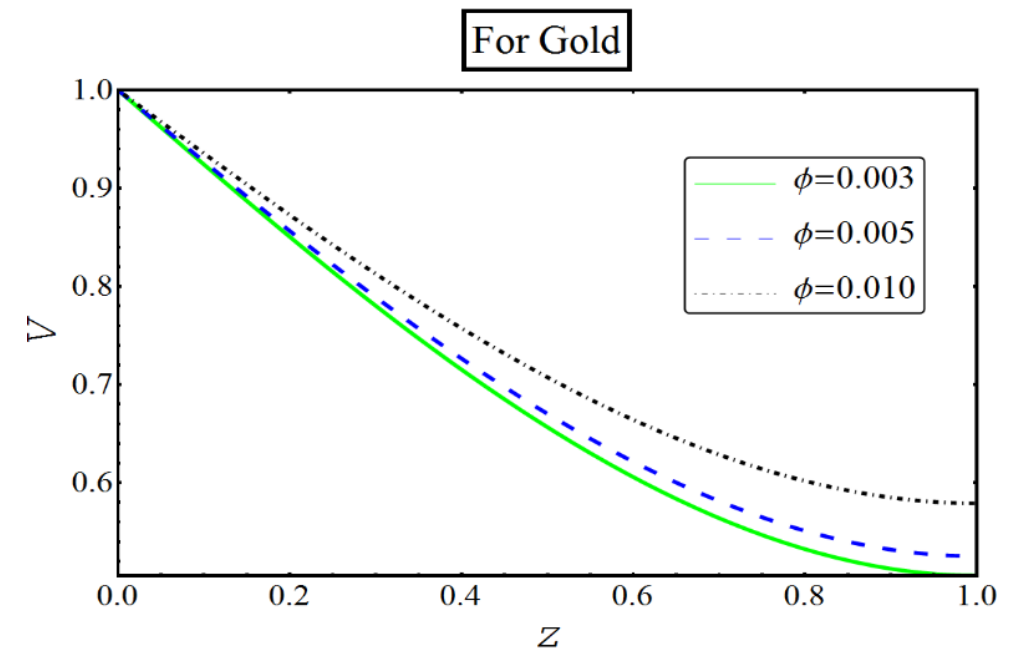

Figure 18. Effects of concentration particles on azimuthal velocity for gold.

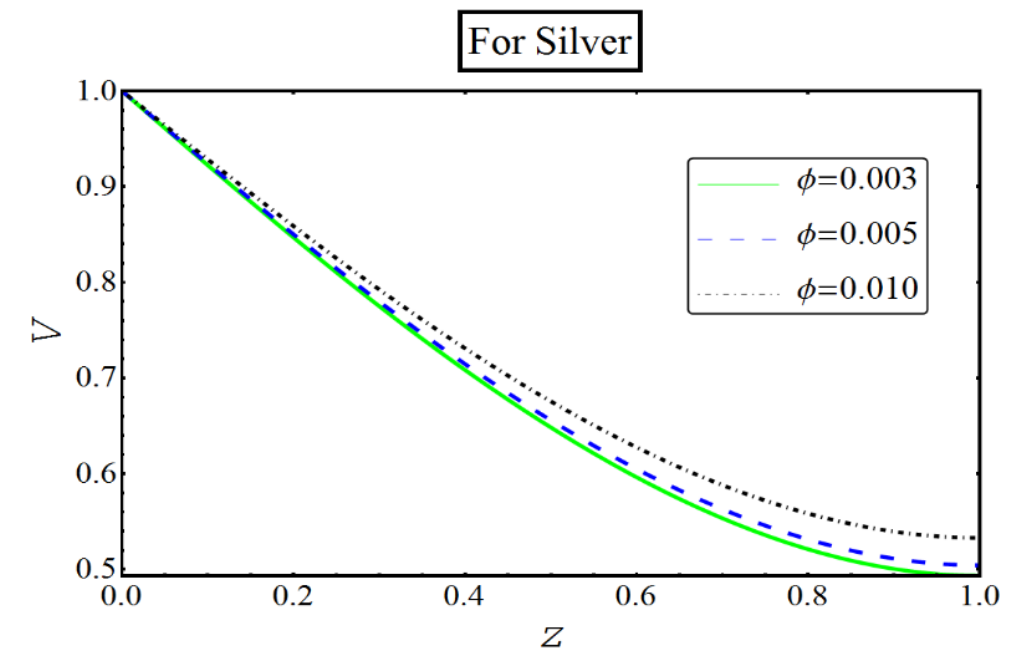

Figure 19. Effects of concentration particles suspended with ethanol on $N$ for silver. 


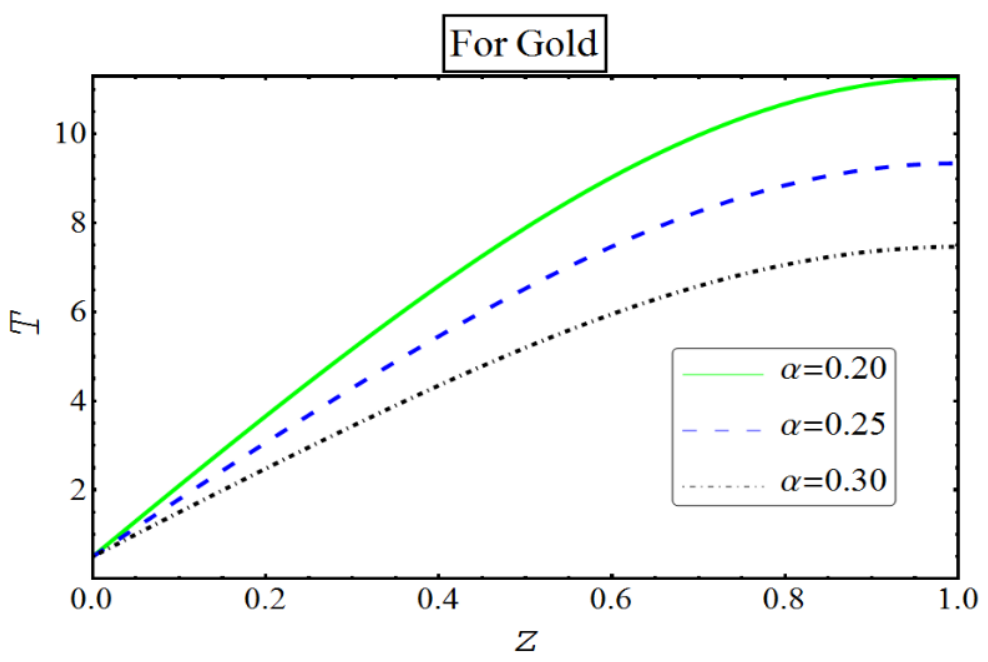

Figure 20. Temperature effects of thermocapillary parameter.

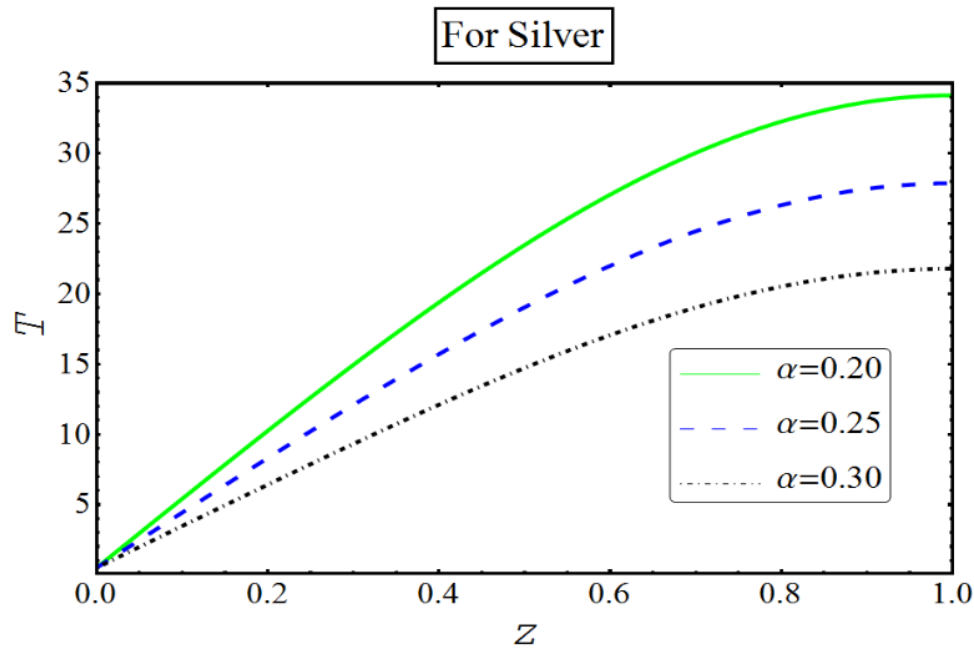

Figure 21. Temperature effects of thermocapillary parameter.

In Equations (58) and (59), $R=\frac{r}{h_{0}}$ is the initial thickness of the film. A similar trend in the behavior of both types of velocities is observed in the presence of silver and gold particles.

In Figures 8-19, the behavior of ethanol is quite prominent for all cases. It is observed that the radial velocity and azimuthal velocity increase for silver and gold. However, radial velocity and azimuthal velocity react quite differently for the thermocapillary parameter and the concentration of the particles. It is seen that temperature increases by increasing the values of thermocapillary parameter, as shown in Figures 20 and 21. It is in accordance with the physical expectation because radial velocity does not allow the fluid to move with full strength. However, the radial velocity is supported by the thermocapillary parameter. On the other hand, a complete reverse trend can be noted for the azimuthal velocity by varying both $\alpha$ and $\varphi$.

\subsection{Thermal Analysis}

In this section, the temperature of nanofluid was examined vertical to the disk. The mathematical relationships for temperature and temperature gradient were respectively denoted by the following relations:

$$
\begin{gathered}
T(z, t)=\frac{R^{2}}{2} \Gamma(z, t)+\tau(z, t) \\
T_{z}(z, t)=\frac{R^{2}}{2} \Gamma_{z}(z, t)+\tau_{z}(z, t)
\end{gathered}
$$


Here smooth and organized curves are drawn in Figures 22-27. It is found that an addition of extra nanoparticles strengthens the drag force between the particles. However, thermocapillary parameter $\alpha$ works altogether differently by reducing the heat of the nanofluid that ultimately affirms the earlier preceding claim regarding the addition of metallic particles to the base fluid ethanol.

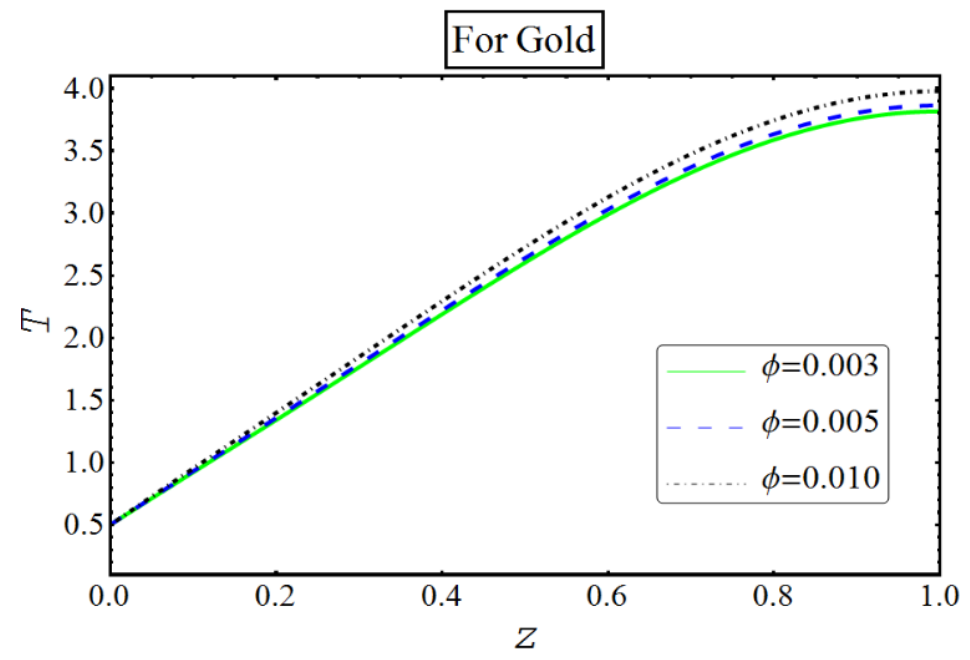

Figure 22. Temperature effects of concentration particles.

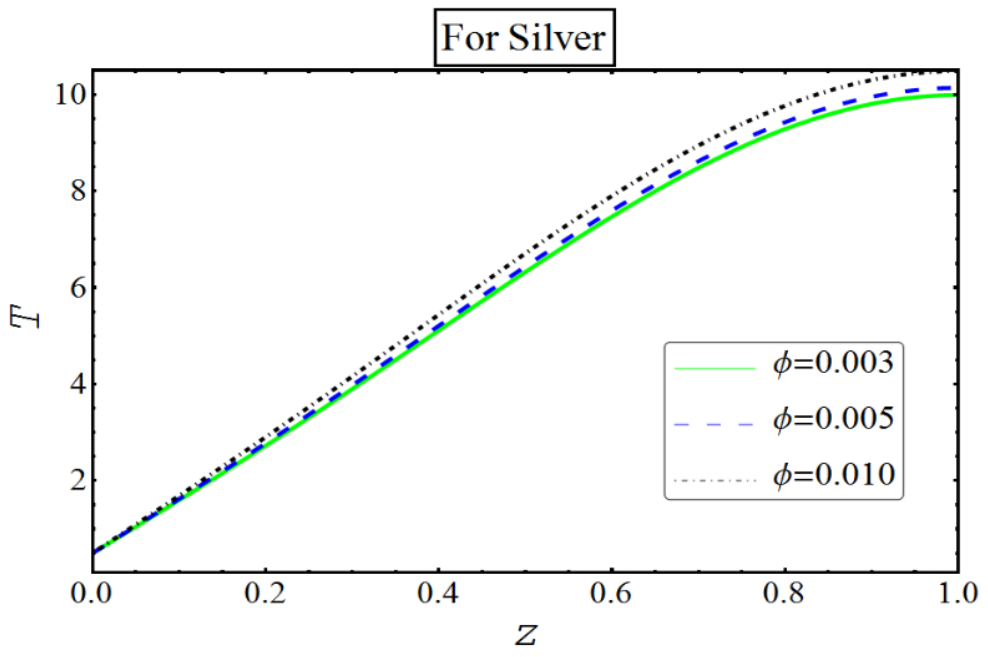

Figure 23. Temperature effects of concentration particles.

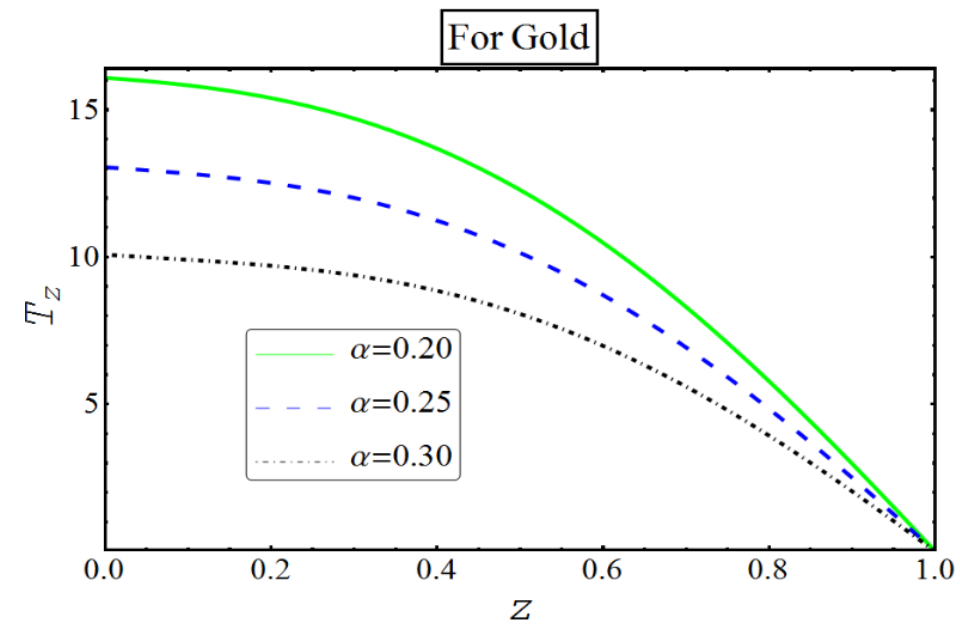

Figure 24. Variation of $T_{z}$ for the thermocapillary parameter. 


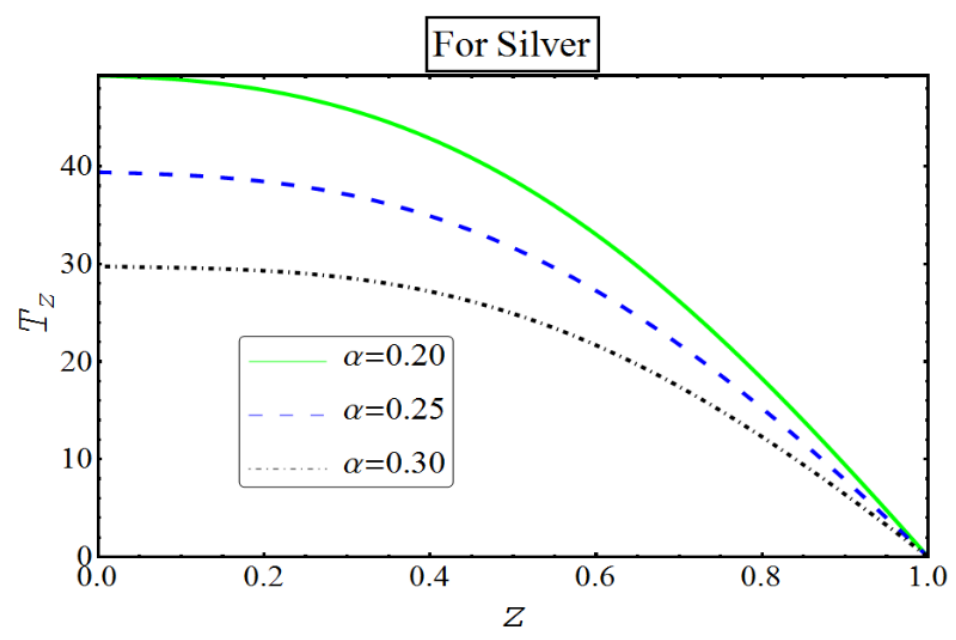

Figure 25. Variation of $T_{z}$ for the thermocapillary parameter.

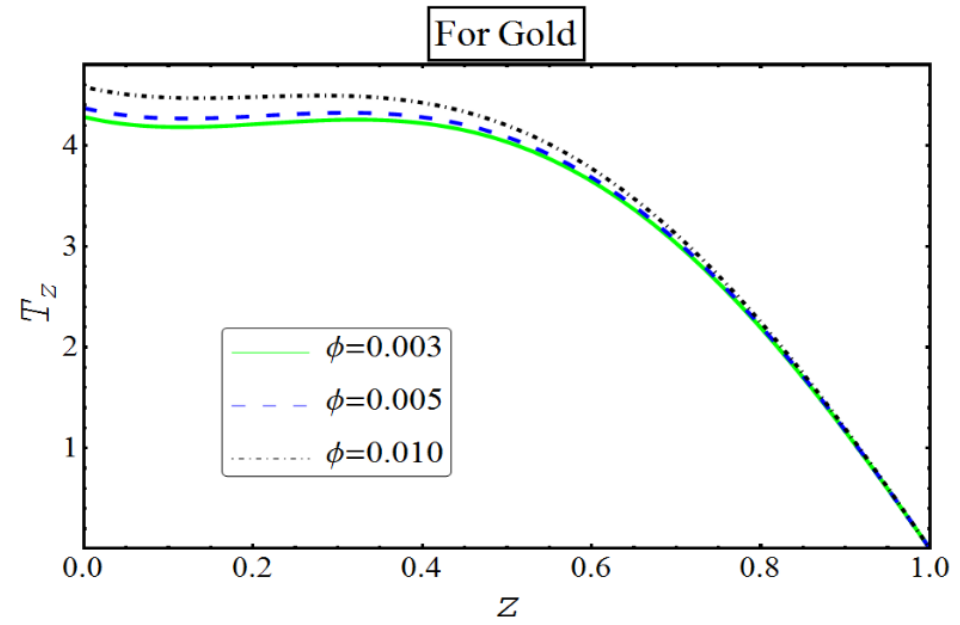

Figure 26. Variation of $T_{z}$ on concentration particles.

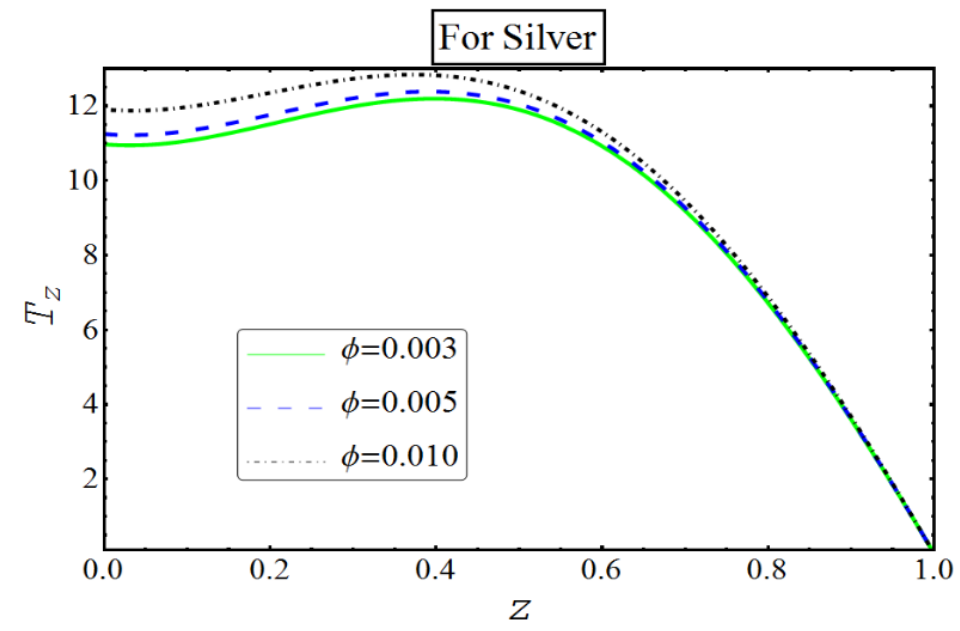

Figure 27. Variation of $T_{z}$ on concentration particles. 


\section{Conclusions}

A comparative study for silver and gold nanoparticles was comprehensively carried out to form a thin and shiny metallic layer over the surface of a rotating disk via spin coatings. Moreover, a detailed analysis of nanofluids suspended with four different types of base fluids, namely water, ethanol, methanol and ethylene-glycol has also been examined under the assumptions of nanofluids to be diluted and non-volatile. Finally, a parametric study on the basis of obtained expressions of results was made to apprehend the effects of the main parameters involved. Some significant findings are enlisted below:

- Silver metallic coating quickly settles down on the surface of the disk than to develop a gold coating.

- Thickness of the film increases with the addition of extra metallic particles.

- Radial velocity is hampered by adding more nanoparticles.

- Increase in the quantity of particles surges the thermal effects of the nanofluid.

- It is worth investigating that these results will help to choose the optimum base fluid with gold or silver particles.

- The graphical results show depletion of the fluid layer with time and one can hardly find such an evaluation in the available literature.

- Finally, it is concluded that the base fluid is the best choice for ethanol alloys with silver in the process of coating. In this way, it can be concluded that from the experimental point of view if silver alloy is used for coating then only such liquids should be considered which exhibit ethanol-like properties. Now, this effort is available for further experimental studies for those who are working in this regime for the validation of their lab results.

Author Contributions: Supervision, R.E.; Investigation, A.Z.; Methodology, F.H.; Writing-Review \& Editing, T.A. Funding: This research received no external funding.

Acknowledgments: F. Hussain gratefully thanks to FBAS to provide him administrative and technical support during his stay at IIUI as HEC indigenous scholar for the pursuance of his Ph.D. studies.

Conflicts of Interest: The authors declare no conflict of interest.

\section{Nomenclatures}

$\begin{array}{ll}h_{0} & \text { Initial film thickness } \\ p & \text { Pressure } \\ t & \text { Spinning time } \\ U & \text { Radial velocity component } \\ V & \text { Velocity } \\ W & \text { Axial velocity component } \\ z & \text { Axial coordinate } \\ \operatorname{Pr} & \text { Prandtl number } \\ \operatorname{Re} & \text { Reynolds number } \\ \bar{h} & \text { Film thickness } \\ \bar{r} & \text { Radial coordinate } \\ \bar{T} & \text { Temperature of nanofluid } \\ \bar{T} & \text { Initial room temperature } \\ \bar{T}_{g} & \text { Temperature in gas phase } \\ \bar{u} & \text { Radial velocity component } \\ \bar{v} & \text { Azimuthal velocity component } \\ \bar{w} & \text { Axial velocity component } \\ k_{n f} & \text { Thermal conductivity of nanofluid } \\ k_{f} & \text { Thermal conductivity of fluid }\end{array}$




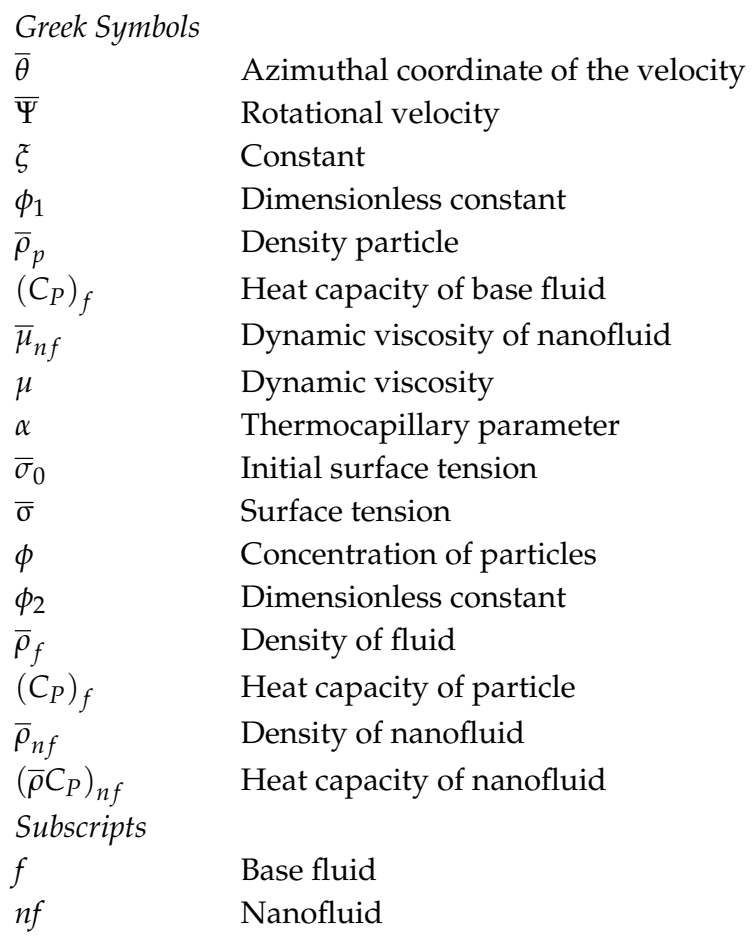

\section{Appendix A}

$$
\begin{aligned}
& f_{1}(t)=H+\alpha(1-\phi)^{2.5}-\frac{3 H^{4} R e \phi_{1}}{4}+\frac{3 H^{5} R e \phi_{1}}{20}-\frac{H^{2} \frac{\mathrm{d} H}{d t} R e \phi_{1}}{2}+\frac{131 H^{5} \frac{\mathrm{d} H}{d t} R e^{2} \phi_{1}}{60}-\frac{53 H^{6} \frac{\mathrm{d} H}{d t} R e^{2} \phi_{1}}{72}+ \\
& \frac{H^{3}\left(\frac{\mathrm{d} H}{d t}\right)^{2} R e^{2} \phi_{1}}{2}+\frac{5 H^{4} \frac{d^{2} H}{d t^{2}} R e^{2} \phi_{1}}{24}+\frac{H^{3} \operatorname{Re} \alpha(1-\phi)^{2.5} \phi_{1}}{3}-\frac{5 H^{4} \operatorname{Re} \alpha(1-\phi)^{2.5} \phi_{1}}{4}-\frac{H^{4} \frac{\mathrm{d} H}{d t} \operatorname{Re}^{2} \alpha(1-\phi)^{2.5} \phi_{1}}{2}+ \\
& \frac{63 H^{5} \frac{\mathrm{d} H}{d t} \operatorname{Re}^{2} \alpha(1-\phi)^{2.5} \phi_{1}}{20}+\frac{31 H^{7} \operatorname{Re}^{2} \phi_{1}^{2}}{45}-\frac{293 H^{8} \operatorname{Re}^{2} \phi_{1}^{2}}{2016}+\frac{12869 H^{9} \operatorname{Re}^{2} \phi_{1}^{2}}{90720}-\frac{3751 H^{10} \mathrm{Re}^{2} \phi_{1}^{2}}{151200}+\frac{67 H^{6} \frac{\mathrm{d} H}{d t} \operatorname{Re}^{2} \phi_{1}^{2}}{180}+ \\
& \frac{8 H^{7} \frac{\mathrm{d} H}{\mathrm{dt}} \operatorname{Re}^{2} \phi_{1}^{2}}{315}+\frac{1607 H^{7} \operatorname{Re}^{2} \alpha(1-\phi)^{2.5} \phi_{1}^{2}}{1260}-\frac{131 H^{8} \operatorname{Re}^{2} \alpha(1-\phi)^{2.5} \phi_{1}^{2}}{1120}+\frac{18679 H^{9} \operatorname{Re}^{2} \alpha(1-\phi)^{2.5} \phi_{1}^{2}}{90720}+\frac{7 H^{5} \frac{\mathrm{d} H}{d t} \operatorname{Re}^{2} \alpha(1-\phi)^{2.5} \phi_{1}^{2}}{60}- \\
& \frac{7 H^{6} \frac{\mathrm{d} H}{d t} \operatorname{Re}^{2} \alpha(1-\phi)^{2.5} \phi_{1}^{2}}{72}-\frac{4 H^{6} \operatorname{Re}^{2} \alpha^{2}(1-\phi)^{5} \phi_{1}^{2}}{45}+\frac{667 H^{7} \operatorname{Re}^{2} \alpha^{2}(1-\phi)^{5} \phi_{1}^{2}}{630}-\frac{4303 H^{8} \operatorname{Re}^{2} \alpha^{2}(1-\phi)^{5} \phi_{1}^{2}}{10080}+\frac{121 H^{12} \operatorname{Re}^{2} \phi_{1}^{3}}{1296}- \\
& \frac{407 H^{13} \operatorname{Re}^{2} \phi_{1}^{3}}{11340}+\frac{1369 H^{14} \operatorname{Re}^{2} \phi_{1}^{3}}{396900}+\frac{55 H^{10} \frac{\mathrm{d} H}{d t} \operatorname{Re}^{2} \phi_{1}^{3}}{432}-\frac{37 H^{11} \frac{\mathrm{d} H}{d t} \operatorname{Re}^{2} \phi_{1}^{3}}{1512}+\frac{25 H^{8}\left(\frac{\mathrm{d} H}{\mathrm{dt}}\right)^{2} \operatorname{Re}^{2} \phi_{1}^{3}}{576}-\frac{11 H^{11} \operatorname{Re}^{2} \alpha(1-\phi)^{2.5} \phi_{1}^{3}}{120}+ \\
& \frac{38573 H^{12} \operatorname{Re}^{2} \alpha(1-\phi)^{2.5} \phi_{1}^{3}}{113400}-\frac{703 H^{13} \operatorname{Re}^{2} \alpha(1-\phi)^{2.5} \phi_{1}^{3}}{11340}-\frac{H^{9} \frac{\mathrm{dH}}{d t} \operatorname{Re}^{2} \alpha(1-\phi)^{2.5} \phi_{1}^{3}}{16}+\frac{95 H^{10} \frac{\mathrm{d} H}{d t} \operatorname{Re}^{2} \alpha(1-\phi)^{2.5} \phi_{1}^{3}}{432}+ \\
& \frac{9 H^{10} \operatorname{Re}^{2} \alpha^{2}(1-\phi)^{5} \phi_{1}^{3}}{400}-\frac{19 H^{11} \operatorname{Re}^{2} \alpha^{2}(1-\phi)^{5} \phi_{1}^{3}}{120}+\frac{361 H^{12} \operatorname{Re}^{2} \alpha^{2}(1-\phi)^{5} \phi_{1}^{3}}{1296} ; \\
& f_{2}(t)=-\frac{1}{2} \\
& f_{3}(t)=\frac{H^{2} \operatorname{Re} \phi_{1}}{3}-\frac{H^{3} \operatorname{Re} \phi_{1}}{9}+\frac{\frac{\mathrm{d} H}{d t} \operatorname{Re} \phi_{1}}{6}-\frac{5 H^{3} \frac{\mathrm{d} H}{d t} \operatorname{Re}^{2} \phi_{1}}{6}+\frac{7 H^{4} \frac{\mathrm{d} H}{d t} \operatorname{Re}^{2} \phi_{1}}{24}-\frac{H\left(\frac{\mathrm{d} H}{d t}\right)^{2} \operatorname{Re}^{2} \phi_{1}}{6}-\frac{\operatorname{Re}^{2} \phi_{1} H^{2} \frac{d^{2} H}{d t^{2}}}{12}+ \\
& \frac{H^{2} \operatorname{Re} \alpha(1-\phi)^{2.5} \phi_{1}}{3}+\frac{H^{2} \frac{\mathrm{d} H}{d t} \operatorname{Re}^{2} \alpha(1-\phi)^{2.5} \phi_{1}}{6}-\frac{7 H^{3} \frac{\mathrm{d} H}{d t} \operatorname{Re}^{2} \alpha(1-\phi)^{2.5} \phi_{1}}{6}-\frac{8 H^{5} \operatorname{Re}^{2} \phi_{1}^{2}}{45}-\frac{H^{6} \operatorname{Re}^{2} \phi_{1}^{2}}{108}-\frac{8 H^{7} \operatorname{Re}^{2} \phi_{1}^{2}}{315}+\frac{H^{8} \operatorname{Re}^{2} \phi_{1}^{2}}{160}- \\
& \frac{5 H^{4} \frac{\mathrm{d} H}{d t} \operatorname{Re}^{2} \phi_{1}^{2}}{36}-\frac{23 H^{5} \operatorname{Re}^{2} \alpha(1-\phi)^{2.5} \phi_{1}^{2}}{90}-\frac{5 H^{6} \operatorname{Re}^{2} \alpha(1-\phi)^{2.5} \phi_{1}^{2}}{54}-\frac{11 H^{7} \operatorname{Re}^{2} \alpha(1-\phi)^{2.5} \phi_{1}^{2}}{270}-\frac{8 H^{5} \operatorname{Re}^{2} \alpha^{2}(1-\phi)^{5} \phi_{1}^{2}}{45}+ \\
& \frac{7 H^{6} \operatorname{Re}^{2} \alpha^{2}(1-\phi)^{5} \phi_{1}^{2}}{108} \\
& f_{4}(t)=-\frac{H \operatorname{Re} \phi_{1}}{12}+\frac{H^{2} \operatorname{Re} \phi_{1}}{12}-\frac{\operatorname{Re} \alpha(1-\phi)^{2.5} \phi_{1}}{12}+\frac{H \operatorname{Re} \alpha(1-\phi)^{2.5} \phi_{1}}{12}-\frac{H^{4} \operatorname{Re}^{2} \phi_{1}^{2}}{12}-\frac{H^{5} \operatorname{Re}^{2} \phi_{1}^{2}}{144}+\frac{7 H^{6} \operatorname{Re}^{2} \phi_{1}^{2}}{2160}-\frac{H^{3} \frac{\mathrm{d} H}{d t} \operatorname{Re}^{2} \phi_{1}^{2}}{24}- \\
& \frac{29 H^{4} \operatorname{Re}^{2} \alpha(1-\phi)^{2.5} \phi_{1}^{2}}{144}-\frac{13 H^{5} \operatorname{Re}^{2} \alpha(1-\phi)^{2.5} \phi_{1}^{2}}{360}-\frac{H^{2} \frac{\mathrm{d} H}{d t} \operatorname{Re}^{2} \alpha(1-\phi)^{2.5} \phi_{1}^{2}}{24}+\frac{H^{3} \operatorname{Re}^{2} \alpha^{2}(1-\phi)^{5} \phi_{1}^{2}}{36}-\frac{3 H^{4} \operatorname{Re}^{2} \alpha^{2}(1-\phi)^{5} \phi_{1}^{2}}{16} ;
\end{aligned}
$$


$f_{5}(t)=\frac{\operatorname{Re} \phi_{1}}{60}-\frac{H \operatorname{Re} \phi_{1}}{30}+\frac{H \frac{\mathrm{d} H}{d t} \operatorname{Re}^{2} \phi_{1}}{15}-\frac{H^{2} \frac{\mathrm{d} H}{d t} \operatorname{Re}^{2} \phi_{1}}{30}+\frac{\frac{d^{2} H}{d t^{2}} \operatorname{Re}^{2} \phi_{1}}{120}-\frac{\operatorname{Re} \alpha(1-\phi)^{2.5} \phi_{1}}{60}+\frac{H \frac{\mathrm{d} H}{d t} \operatorname{Re}^{2} \alpha(1-\phi)^{2.5} \phi_{1}}{15}+\frac{H^{4} \operatorname{Re}^{2} \phi_{1}^{2}}{16}-$ $\frac{H^{5} \operatorname{Re}^{2} \phi_{1}^{2}}{80}+\frac{H^{2} \frac{\mathrm{d} H}{d t} \operatorname{Re}^{2} \phi_{1}^{2}}{24}-\frac{H^{3} \operatorname{Re}^{2} \alpha(1-\phi)^{2.5} \phi_{1}^{2}}{36}+\frac{17 H^{4} \operatorname{Re}^{2} \alpha(1-\phi)^{2.5} \phi_{1}^{2}}{120}-\frac{3 H^{5} \operatorname{Re}^{2} \alpha(1-\phi)^{2.5} \phi_{1}^{2}}{400}+\frac{H^{2} \frac{\mathrm{d} H}{d t} \operatorname{Re}^{2} \alpha(1-\phi)^{2.5} \phi_{1}^{2}}{40}-$ $\frac{H^{3} \operatorname{Re}^{2} \alpha^{2}(1-\phi)^{5} \phi_{1}^{2}}{60}+\frac{H^{4} \operatorname{Re}^{2} \alpha^{2}(1-\phi)^{5} \phi_{1}^{2}}{16}-\frac{9 H^{8} \operatorname{Re}^{2} \phi_{1}^{3}}{320}+\frac{9 H^{9} \operatorname{Re}^{2} \phi_{1}^{3}}{800}-\frac{9 H^{10} \operatorname{Re}^{2} \phi_{1}^{3}}{8000}-\frac{3 H^{6} \frac{\mathrm{dH}}{\mathrm{dt}} \operatorname{Re}^{2} \phi_{1}^{3}}{80}+\frac{3 H^{7} \frac{\mathrm{dH}}{d t} \operatorname{Re}^{2} \phi_{1}^{3}}{400}-$ $\frac{H^{4}\left(\frac{d H}{d t}\right)^{2} \operatorname{Re}^{2} \phi_{1}^{3}}{80}+\frac{H^{7} \operatorname{Re}^{2} \alpha(1-\phi)^{2.5} \phi_{1}^{3}}{40}-\frac{79 H^{8} \operatorname{Re}^{2} \alpha(1-\phi)^{2.5} \phi_{1}^{3}}{800}+\frac{3 H^{9} \operatorname{Re}^{2} \alpha(1-\phi)^{2.5} \phi_{1}^{3}}{160}+\frac{H^{5} \frac{\mathrm{d} H}{d t} \operatorname{Re}^{2} \alpha(1-\phi)^{2.5} \phi_{1}^{3}}{60}-$ $\frac{H^{6} \frac{\mathrm{d} H}{d t} \operatorname{Re}^{2} \alpha(1-\phi)^{2.5} \phi_{1}^{3}}{16}-\frac{H^{6} \operatorname{Re}^{2} \alpha^{2}(1-\phi)^{5} \phi_{1}^{3}}{180}+\frac{H^{7} \operatorname{Re}^{2} \alpha^{2}(1-\phi)^{5} \phi_{1}^{3}}{24}-\frac{5 H^{8} \operatorname{Re}^{2} \alpha^{2}(1-\phi)^{5} \phi_{1}^{3}}{64} ;$

$f_{6}(t)=\frac{\operatorname{Re} \phi_{1}}{360}-\frac{\frac{\mathrm{d} H}{d t} \operatorname{Re}^{2} \phi_{1}}{360}+\frac{H \frac{\mathrm{d} H}{d t} \operatorname{Re}^{2} \phi_{1}}{180}+\frac{\frac{\mathrm{d} H}{d t} \operatorname{Re}^{2} \alpha(1-\phi)^{2.5} \phi_{1}}{360}+\frac{H^{2} \operatorname{Re}^{2} \phi_{1}^{2}}{30}+\frac{H^{3} \operatorname{Re}^{2} \phi_{1}^{2}}{180}-\frac{H^{4} \operatorname{Re}^{2} \phi_{1}^{2}}{72}+\frac{H^{5} \operatorname{Re}^{2} \phi_{1}^{2}}{600}+$ $\frac{H \frac{\mathrm{d} H}{d t} \operatorname{Re}^{2} \phi_{1}^{2}}{120}-\frac{H^{2} \frac{\mathrm{d} H}{d t} \operatorname{Re}^{2} \phi_{1}^{2}}{180}+\frac{H^{2} \operatorname{Re}^{2} \alpha(1-\phi)^{2.5} \phi_{1}^{2}}{12}+\frac{H^{3} \operatorname{Re}^{2} \alpha(1-\phi)^{2.5} \phi_{1}^{2}}{270}-\frac{H^{4} \operatorname{Re}^{2} \alpha(1-\phi)^{2.5} \phi_{1}^{2}}{72}+\frac{\frac{\mathrm{d} H}{d t} \operatorname{Re}^{2} \alpha(1-\phi)^{2.5} \phi_{1}^{2}}{120}+$ $\frac{H^{2} \operatorname{Re}^{2} \alpha^{2}(1-\phi)^{5} \phi_{1}^{2}}{20}$

$f_{7}(t)=-\frac{\operatorname{Re}^{2} \phi_{1} \frac{\mathrm{d} H}{d t}}{1260}-\frac{8 H^{2} \operatorname{Re}^{2} \phi_{1}^{2}}{315}+\frac{2 H^{3} \operatorname{Re}^{2} \phi_{1}^{2}}{189}-\frac{17 \operatorname{Re}^{2} \phi_{1}^{2} \frac{\mathrm{d} H}{d t}}{2520}-\frac{2 H \operatorname{Re}^{2} \alpha(1-\phi)^{2.5} \phi_{1}^{2}}{315}-\frac{11 H^{2} \operatorname{Re}^{2} \alpha(1-\phi)^{2.5} \phi_{1}^{2}}{420}+$ $\frac{13 H^{3} \operatorname{Re}^{2} \alpha(1-\phi)^{2.5} \phi_{1}^{2}}{3780}-\frac{\frac{\mathrm{d} H}{d t} \operatorname{Re}^{2} \alpha(1-\phi)^{2.5} \phi_{1}^{2}}{252}-\frac{\operatorname{Re}^{2} \alpha^{2}(1-\phi)^{5} \phi_{1}^{2}}{315}+\frac{H \operatorname{Re}^{2} \alpha^{2}(1-\phi)^{5} \phi_{1}^{2}}{315}-\frac{13 H^{2} \operatorname{Re}^{2} \alpha^{2}(1-\phi)^{5} \phi_{1}^{2}}{1260}+\frac{H^{6} \operatorname{Re}^{2} \phi_{1}^{3}}{112}-$ $\frac{H^{7} \operatorname{Re}^{2} \phi_{1}^{3}}{210}+\frac{H^{8} \operatorname{Re}^{2} \phi_{1}^{3}}{1680}+\frac{H^{4} \frac{d H}{d t} \operatorname{Re}^{2} \phi_{1}^{3}}{96}-\frac{29 H^{5} \frac{d H}{d t} \operatorname{Re}^{2} \phi_{1}^{3}}{10080}+\frac{H^{2}\left(\frac{d H}{d t}\right)^{2} \operatorname{Re}^{2} \phi_{1}^{3}}{336}-\frac{H^{5} \operatorname{Re}^{2} \alpha(1-\phi)^{2.5} \phi_{1}^{3}}{252}+\frac{19 H^{6} \operatorname{Re}^{2} \alpha(1-\phi)^{2.5} \phi_{1}^{3}}{756}-$ $\frac{17 H^{7} \operatorname{Re}^{2} \alpha(1-\phi)^{2.5} \phi_{1}^{3}}{2520}-\frac{H^{3} \frac{\mathrm{d} H}{d t} \operatorname{Re}^{2} \alpha(1-\phi)^{2.5} \phi_{1}^{3}}{504}+\frac{3 H^{4} \frac{\mathrm{d} H}{d t} \operatorname{Re}^{2} \alpha(1-\phi)^{2.5} \phi_{1}^{3}}{224}-\frac{H^{5} \operatorname{Re}^{2} \alpha^{2}(1-\phi)^{5} \phi_{1}^{3}}{252}+\frac{5 H^{6} \operatorname{Re}^{2} \alpha^{2}(1-\phi)^{5} \phi_{1}^{3}}{336} ;$ $f_{8}(t)=-\frac{\operatorname{Re}^{2} \phi_{1}^{2}}{360}+\frac{31 H \operatorname{Re}^{2} \phi_{1}^{2}}{10080}-\frac{H^{2} \operatorname{Re}^{2} \phi_{1}^{2}}{840}-\frac{H^{3} \operatorname{Re}^{2} \phi_{1}^{2}}{1260}+\frac{\operatorname{Re}^{2} \phi_{1}^{2} \frac{\mathrm{d} H}{d t}}{1008}-\frac{5 \operatorname{Re}^{2} \alpha(1-\phi)^{2.5} \phi_{1}^{2}}{2016}-\frac{13 H \operatorname{Re}^{2} \alpha(1-\phi)^{2.5} \phi_{1}^{2}}{5040}+$ $\frac{H^{2} \operatorname{Re}^{2} \alpha(1-\phi)^{2.5} \phi_{1}^{2}}{1120}-\frac{\operatorname{Re}^{2} \alpha^{2}(1-\phi)^{5} \phi_{1}^{2}}{560}-\frac{H \operatorname{Re}^{2} \alpha^{2}(1-\phi)^{5} \phi_{1}^{2}}{672}-\frac{H^{5} \operatorname{Re}^{2} \phi_{1}^{3}}{640}+\frac{3 H^{6} \operatorname{Re}^{2} \phi_{1}^{3}}{1600}-\frac{H^{7} \operatorname{Re}^{2} \phi_{1}^{3}}{3200}-\frac{H^{3} \frac{\mathrm{d} H}{\mathrm{dt}} \operatorname{Re}^{2} \phi_{1}^{3}}{960}+$ $\frac{H^{4} \frac{\mathrm{d} H}{d t} \operatorname{Re}^{2} \phi_{1}^{3}}{960}-\frac{H^{4} \operatorname{Re}^{2} \alpha(1-\phi)^{2.5} \phi_{1}^{3}}{1152}-\frac{41 H^{5} \operatorname{Re}^{2} \alpha(1-\phi)^{2.5} \phi_{1}^{3}}{28800}+\frac{11 H^{6} \operatorname{Re}^{2} \alpha(1-\phi)^{2.5} \phi_{1}^{3}}{4800}-\frac{H^{2} \frac{\mathrm{d} H}{d t} \operatorname{Re}^{2} \alpha(1-\phi)^{2.5} \phi_{1}^{3}}{960}+$ $\frac{H^{3} \frac{\mathrm{d} H}{d t} \operatorname{Re}^{2} \alpha(1-\phi)^{2.5} \phi_{1}^{3}}{960}+\frac{H^{3} \operatorname{Re}^{2} \alpha^{2}(1-\phi)^{5} \phi_{1}^{3}}{1440}-\frac{19 H^{4} \operatorname{Re}^{2} \alpha^{2}(1-\phi)^{5} \phi_{1}^{3}}{5760}+\frac{H^{5} \operatorname{Re}^{2} \alpha^{2}(1-\phi)^{5} \phi_{1}^{3}}{384} ;$ $f_{9}(t)=\frac{83 \operatorname{Re}^{2} \phi_{1}^{2}}{90720}+\frac{H \operatorname{Re}^{2} \phi_{1}^{2}}{2016}+\frac{H^{2} \operatorname{Re}^{2} \phi_{1}^{2}}{2592}+\frac{127 \operatorname{Re}^{2} \alpha(1-\phi)^{2.5} \phi_{1}^{2}}{90720}+\frac{11 H \operatorname{Re}^{2} \alpha(1-\phi)^{2.5} \phi_{1}^{2}}{12960}+\frac{41 \operatorname{Re}^{2} \alpha^{2}(1-\phi)^{5} \phi_{1}^{2}}{90720}-\frac{7 H^{4} \operatorname{Re}^{2} \phi_{1}^{3}}{12960}+$ $\frac{H^{5} \operatorname{Re}^{2} \phi_{1}^{3}}{194400}+\frac{H^{6} \operatorname{Re}^{2} \phi_{1}^{3}}{145800}-\frac{H^{2} \frac{\mathrm{d} H}{d t} \operatorname{Re}^{2} \phi_{1}^{3}}{1620}-\frac{H^{3} \frac{\mathrm{d} H}{d t} \operatorname{Re}^{2} \phi_{1}^{3}}{19440}-\frac{\left(\frac{\mathrm{d} H}{d t}\right)^{2} \operatorname{Re}^{2} \phi_{1}^{3}}{5184}-\frac{H^{3} \operatorname{Re}^{2} \alpha(1-\phi)^{2.5} \phi_{1}^{3}}{9720}-\frac{23 H^{4} \operatorname{Re}^{2} \alpha(1-\phi)^{2.5} \phi_{1}^{3}}{19440}-$ $\frac{41 H^{5} \operatorname{Re}^{2} \alpha(1-\phi)^{2.5} \phi_{1}^{3}}{194400}-\frac{H^{2} \frac{\mathrm{d} H}{d t} \operatorname{Re}^{2} \alpha(1-\phi)^{2.5} \phi_{1}^{3}}{1080}+\frac{H^{3} \operatorname{Re}^{2} \alpha^{2}(1-\phi)^{5} \phi_{1}^{3}}{9720}-\frac{H^{4} \operatorname{Re}^{2} \alpha^{2}(1-\phi)^{5} \phi_{1}^{3}}{864} ;$ $f_{10}(t)=-\frac{41 \operatorname{Re}^{2} \phi_{1}^{2}}{226800}-\frac{H \operatorname{Re}^{2} \phi_{1}^{2}}{8100}-\frac{11 \operatorname{Re}^{2} \alpha(1-\phi)^{2.5} \phi_{1}^{2}}{64800}+\frac{H^{3} \operatorname{Re}^{2} \phi_{1}^{3}}{3600}-\frac{103 H^{4} \operatorname{Re}^{2} \phi_{1}^{3}}{302400}+\frac{131 H^{5} \operatorname{Re}^{2} \phi_{1}^{3}}{1512000}+\frac{H \frac{\mathrm{d} H}{d t} \operatorname{Re}^{2} \phi_{1}^{3}}{7200}-$ $\frac{H^{2} \frac{\mathrm{d} H}{\mathrm{dt}} \operatorname{Re}^{2} \phi_{1}^{3}}{8400}+\frac{H^{2} \operatorname{Re}^{2} \alpha(1-\phi)^{2.5} \phi_{1}^{3}}{3600}-\frac{H^{3} \operatorname{Re}^{2} \alpha(1-\phi)^{2.5} \phi_{1}^{3}}{9450}-\frac{41 H^{4} \operatorname{Re}^{2} \alpha(1-\phi)^{2.5} \phi_{1}^{3}}{302400}+\frac{\operatorname{Re}^{2} \alpha(1-\phi)^{2.5} \phi_{1}^{3} \frac{\mathrm{d} H}{\mathrm{dt}}}{7200}-$ $\frac{H \frac{\mathrm{d} H}{d t} \operatorname{Re}^{2} \alpha(1-\phi)^{2.5} \phi_{1}^{3}}{7200}+\frac{H^{2} \operatorname{Re}^{2} \alpha^{2}(1-\phi)^{5} \phi_{1}^{3}}{3600}-\frac{H^{3} \operatorname{Re}^{2} \alpha^{2}(1-\phi)^{5} \phi_{1}^{3}}{3600} ;$ $f_{11}(t)=\frac{\operatorname{Re}^{2} \phi_{1}^{2}}{64800}-\frac{H^{2} \operatorname{Re}^{2} \phi_{1}^{3}}{14850}+\frac{53 H^{3} \operatorname{Re}^{2} \phi_{1}^{3}}{356400}-\frac{19 H^{4} \operatorname{Re}^{2} \phi_{1}^{3}}{356400}-\frac{\operatorname{Re}^{2} \phi_{1}^{3} \frac{\mathrm{d} H}{d t}}{47520}+\frac{H \frac{\mathrm{d} H}{d t} \operatorname{Re}^{2} \phi_{1}^{3}}{23760}-\frac{H \operatorname{Re}^{2} \alpha(1-\phi)^{2.5} \phi_{1}^{3}}{19800}+$ $\frac{H^{2} \operatorname{Re}^{2} \alpha(1-\phi)^{2.5} \phi_{1}^{3}}{9900}+\frac{7 H^{3} \operatorname{Re}^{2} \alpha(1-\phi)^{2.5} \phi_{1}^{3}}{356400}+\frac{\operatorname{Re}^{2} \alpha(1-\phi)^{2.5} \phi_{1}^{3} \frac{\mathrm{d} H}{d t}}{47520}-\frac{\operatorname{Re}^{2} \alpha^{2}(1-\phi)^{5} \phi_{1}^{3}}{39600}+\frac{H \operatorname{Re}^{2} \alpha^{2}(1-\phi)^{5} \phi_{1}^{3}}{19800}+$ $\frac{H^{2} \operatorname{Re}^{2} \alpha^{2}(1-\phi)^{5} \phi_{1}^{3}}{59400}$

$f_{12}(t)=\frac{H \operatorname{Re}^{2} \phi_{1}^{3}}{129600}-\frac{13 H^{2} \operatorname{Re}^{2} \phi_{1}^{3}}{453600}+\frac{47 H^{3} \operatorname{Re}^{2} \phi_{1}^{3}}{2721600}-\frac{\operatorname{Re}^{2} \phi_{1}^{3} \frac{\mathrm{d} H}{\mathrm{dt}}}{362880}+\frac{\operatorname{Re}^{2} \alpha(1-\phi)^{2.5} \phi_{1}^{3}}{129600}-\frac{H \operatorname{Re}^{2} \alpha(1-\phi)^{2.5} \phi_{1}^{3}}{32400}+$ $\frac{H^{2} \operatorname{Re}^{2} \alpha(1-\phi)^{2.5} \phi_{1}^{3}}{56700}-\frac{\operatorname{Re}^{2} \alpha^{2}(1-\phi)^{5} \phi_{1}^{3}}{129600}+\frac{H \operatorname{Re}^{2} \alpha^{2}(1-\phi)^{5} \phi_{1}^{3}}{129600} ;$

$f_{13}(t)=-\frac{\operatorname{Re}^{2} \phi_{1}^{3}}{1684800}+\frac{H \operatorname{Re}^{2} \phi_{1}^{3}}{294840}-\frac{H^{2} \operatorname{Re}^{2} \phi_{1}^{3}}{294840}+\frac{\operatorname{Re}^{2} \alpha(1-\phi)^{2.5} \phi_{1}^{3}}{453600}-\frac{H \operatorname{Re}^{2} \alpha(1-\phi)^{2.5} \phi_{1}^{3}}{294840}-\frac{\operatorname{Re}^{2} \alpha^{2}(1-\phi)^{5} \phi_{1}^{3}}{1684800} ;$

$f_{14}(t)=-\frac{\operatorname{Re}^{2} \phi_{1}^{3}}{6350400}+\frac{H \operatorname{Re}^{2} \phi_{1}^{3}}{3175200}+\frac{\operatorname{Re}^{2} \alpha(1-\phi)^{2.5} \phi_{1}^{3}}{6350400} ;$

$f_{15}(t)=-\frac{\operatorname{Re}^{2} \phi_{1}^{3}}{95256000}$ 
$g_{1}(t)=-H^{2} \operatorname{Re} \phi_{1}+H^{3} \operatorname{Re}^{2} \phi_{1} \frac{\mathrm{d} H}{d t}-H^{2} \operatorname{Re} \alpha(1-\phi)^{2.5} \phi_{1}+H^{3} \operatorname{Re}^{2} \alpha \phi_{1} \frac{\mathrm{d} H}{d t}(1-\phi)^{2.5}-\frac{H^{4} \operatorname{Re}^{2} \phi_{1} \frac{\mathrm{d} H}{d t}}{2}+$ $\frac{8 H^{5} \operatorname{Re}^{2} \phi_{1}^{2}}{15}+\frac{H^{3} \operatorname{Re} \phi_{1}}{3}+\frac{H^{6} \operatorname{Re}^{2} \phi_{1}^{2}}{36}+\frac{8 H^{7} \operatorname{Re}^{2} \phi_{1}^{2}}{105}-\frac{3 H^{8} \operatorname{Re}^{2} \phi_{1}^{2}}{160}+\frac{5 H^{4} \operatorname{Re}^{2} \phi_{1}^{2} \frac{\mathrm{d} H}{d t}}{12}+\frac{23 H^{5} \operatorname{Re}^{2} \alpha(1-\phi)^{2.5} \phi_{1}^{2}}{30}+$ $\frac{5 H^{6} \operatorname{Re}^{2} \alpha(1-\phi)^{2.5} \phi_{1}^{2}}{18}+\frac{11 H^{7} \operatorname{Re}^{2} \alpha(1-\phi)^{2.5} \phi_{1}^{2}}{90}+\frac{8 H^{5} \operatorname{Re}^{2} \alpha^{2}(1-\phi)^{5} \phi_{1}^{2}}{15}-\frac{7 H^{6} \operatorname{Re}^{2} \alpha^{2}(1-\phi)^{5} \phi_{1}^{2}}{36} ;$

$g_{2}(t)=0$

$g_{3}(t)=\frac{\operatorname{Re} \phi_{1}}{3}-\frac{H \operatorname{Re}^{2} \phi_{1} \frac{\mathrm{d} H}{d t}}{3}+\frac{H^{2} \operatorname{Re}^{2} \phi_{1} \frac{\mathrm{d} H}{d t}}{6}+\frac{\operatorname{Re} \alpha(1-\phi)^{2.5} \phi_{1}}{3}-\frac{H \operatorname{Re}^{2} \alpha(1-\phi)^{2.5} \phi_{1} \frac{\mathrm{d} H}{d t}}{3}-\frac{H^{4} \operatorname{Re}^{2} \phi_{1}^{2}}{4}+\frac{H^{5} \operatorname{Re}^{2} \phi_{1}^{2}}{20}-$ $\frac{H^{2} \operatorname{Re}^{2} \phi_{1}^{2} \frac{\mathrm{d} H}{d t}}{6}+\frac{H^{3} \operatorname{Re}^{2} \alpha(1-\phi)^{2.5} \phi_{1}^{2}}{9}-\frac{5 H^{4} \operatorname{Re}^{2} \alpha(1-\phi)^{2.5} \phi_{1}^{2}}{12} ;$

$g_{4}(t)=-\frac{\operatorname{Re} \phi_{1}}{12}-\frac{H^{2} \operatorname{Re}^{2} \phi_{1}^{2}}{6}+\frac{H^{3} \operatorname{Re}^{2} \phi_{1}^{2}}{18}-\frac{H^{2} \operatorname{Re}^{2} \alpha(1-\phi)^{2.5} \phi_{1}^{2}}{3}+\frac{H^{3} \operatorname{Re}^{2} \alpha(1-\phi)^{2.5} \phi_{1}^{2}}{18}-\frac{H^{2} \operatorname{Re}^{2} \alpha^{2}(1-\phi)^{5} \phi_{1}^{2}}{6} ;$

$g_{5}(t)=\frac{2 H^{2} \operatorname{Re}^{2} \phi_{1}^{2}}{15}-\frac{2 H^{3} \operatorname{Re}^{2} \phi_{1}^{2}}{45}+\frac{\operatorname{Re}^{2} \phi_{1}^{2} \frac{\mathrm{d} H}{d t}}{60}+\frac{11 H^{2} \operatorname{Re}^{2} \alpha(1-\phi)^{2.5} \phi_{1}^{2}}{60}-\frac{H^{3} \operatorname{Re}^{2} \alpha(1-\phi)^{2.5} \phi_{1}^{2}}{60}+\frac{H^{2} \operatorname{Re}^{2} \alpha^{2}(1-\phi)^{5} \phi_{1}^{2}}{20} ;$

$g_{6}(t)=\frac{\operatorname{Re}^{2} \phi_{1}^{2}}{45}-\frac{H \operatorname{Re}^{2} \phi_{1}^{2}}{180}-\frac{H^{2} \operatorname{Re}^{2} \phi_{1}^{2}}{180}+\frac{H^{3} \operatorname{Re}^{2} \phi_{1}^{2}}{270}+\frac{7 \operatorname{Re}^{2} \alpha(1-\phi)^{2.5} \phi_{1}^{2}}{180}+\frac{H \operatorname{Re}^{2} \alpha(1-\phi)^{2.5} \phi_{1}^{2}}{180}-\frac{H^{2} \operatorname{Re}^{2} \alpha(1-\phi)^{2.5} \phi_{1}^{2}}{90}+$ $\frac{\operatorname{Re}^{2} \alpha^{2}(1-\phi)^{5} \phi_{1}^{2}}{45} ;$

$g_{7}(t)=-\frac{2 \operatorname{Re}^{2} \phi_{1}^{2}}{105}-\frac{H \operatorname{Re}^{2} \phi_{1}^{2}}{630}-\frac{\operatorname{Re}^{2} \alpha(1-\phi)^{2.5} \phi_{1}^{2}}{35}-\frac{\operatorname{Re}^{2} \alpha^{2}(1-\phi)^{5} \phi_{1}^{2}}{126} ;$

$g_{8}(t)=\frac{17 \operatorname{Re}^{2} \phi_{1}^{2}}{3360}+\frac{\operatorname{Re}^{2} \alpha(1-\phi)^{2.5} \phi_{1}^{2}}{288} ;$

$g_{9}(t)=-\frac{\operatorname{Re}^{2} \phi_{1}^{2}}{2592}$

$m_{1}(t)=-\frac{H^{2} \operatorname{Re}}{A_{2}}+\frac{H^{3} \operatorname{Re}}{3 A_{2}}+\frac{2 H^{5} \operatorname{Re}^{2}}{5 A_{2}{ }^{2}}-\frac{11 H^{6} \mathrm{Re}^{2}}{36 A_{2}{ }^{2}}+\frac{5 H^{7} \mathrm{Re}^{2}}{84 A_{2}{ }^{2}}+\frac{H^{3} \frac{d^{2} H}{d t^{2}} \operatorname{Re}^{2}}{A_{2}{ }^{2}}-\frac{H^{4} \frac{d^{2} H}{d t^{2}} \operatorname{Re}^{2}}{2 A_{2}{ }^{2}}-\frac{H^{2} \operatorname{Re} \alpha(1-\phi)^{2.5}}{A_{2}}+$ $\frac{4 H^{5} \operatorname{Re}^{2} \alpha(1-\phi)^{2.5}}{5 A_{2}{ }^{2}}-\frac{11 H^{6} \operatorname{Re}^{2} \alpha(1-\phi)^{2.5}}{36 A_{2}{ }^{2}}+\frac{H^{3} \frac{d^{2} H}{d t^{2}} \operatorname{Re}^{2} \alpha(1-\phi)^{2.5}}{A_{2}{ }^{2}}+\frac{2 H^{5} \operatorname{Re}^{2} \alpha^{2}(1-\phi)^{5}}{5 A_{2}{ }^{2}}+\frac{11 H^{6} \operatorname{Re}^{2} \phi_{1}}{18 A_{2}}-\frac{37 H^{7} \operatorname{Re}^{2} \phi_{1}}{315 A_{2}}+$ $\frac{5 H^{4} \frac{d^{2} H}{d t^{2}} \operatorname{Re}^{2} \phi_{1}}{12 A_{2}}-\frac{3 H^{5} \operatorname{Re}^{2} \alpha(1-\phi)^{2.5} \phi_{1}}{10 A_{2}}+\frac{19 H^{6} \operatorname{Re}^{2} \alpha(1-\phi)^{2.5} \phi_{1}}{18 A_{2}} ;$

$m_{2}(t)=0 ;$

$m_{3}(t)=\frac{\operatorname{Re}}{3 A_{2}}-\frac{H \frac{d^{2} H}{d t^{2}} \operatorname{Re}^{2}}{3 A_{2}{ }^{2}}+\frac{H^{2} \frac{d^{2} H}{d t^{2}} \operatorname{Re}^{2}}{6 A_{2}{ }^{2}}+\frac{\operatorname{Re} \alpha(1-\phi)^{2.5}}{3 A_{2}}-\frac{H \frac{d^{2} H}{d t^{2}} \operatorname{Re}^{2} \alpha(1-\phi)^{2.5}}{3 A_{2}{ }^{2}}-\frac{H^{4} \operatorname{Re}^{2} \phi_{1}}{4 A_{2}}+\frac{H^{5} \operatorname{Re}^{2} \phi_{1}}{20 A_{2}}-$ $\frac{H^{2} \frac{d^{2} H}{d t^{2}} \operatorname{Re}^{2} \phi_{1}}{6 A_{2}}+\frac{H^{3} \operatorname{Re}^{2} \alpha(1-\phi)^{2.5} \phi_{1}}{9 A_{2}}-\frac{5 H^{4} \operatorname{Re}^{2} \alpha(1-\phi)^{2.5} \phi_{1}}{12 A_{2}} ;$

$m_{4}(t)=-\frac{\operatorname{Re}}{12 A_{2}}-\frac{H^{2} \operatorname{Re}^{2}}{12 A_{2}{ }^{2}}+\frac{H^{3} \operatorname{Re}^{2}}{36 A_{2} 2^{2}}-\frac{H^{2} \operatorname{Re}^{2} \alpha(1-\phi)^{2.5}}{6 A_{2}{ }^{2}}+\frac{H^{3} \operatorname{Re}^{2} \alpha(1-\phi)^{2.5}}{36 A_{2}{ }^{2}}-\frac{H^{2} \operatorname{Re}^{2} \alpha^{2}(1-\phi)^{5}}{12 A_{2}{ }^{2}} ;$

$m_{5}(t)=\frac{H^{2} \mathrm{Re}^{2}}{30 A_{2}{ }^{2}}-\frac{H^{3} \mathrm{Re}^{2}}{90 A_{2}{ }^{2}}+\frac{H^{2} \operatorname{Re}^{2} \alpha(1-\phi)^{2.5}}{30 A_{2}{ }^{2}}+\frac{H^{2} \operatorname{Re}^{2} \phi_{1}}{30 A_{2}}-\frac{H^{3} \operatorname{Re}^{2} \phi_{1}}{90 A_{2}}+\frac{\frac{d^{2} H}{d t^{2}} \operatorname{Re}^{2} \phi_{1}}{60 A_{2}}+\frac{H^{2} \operatorname{Re}^{2} \alpha(1-\phi)^{2.5} \phi_{1}}{30 A_{2}} ;$

$m_{6}(t)=-\frac{\operatorname{Re}^{2}}{90 A_{2}{ }^{2}}-\frac{\operatorname{Re}^{2} \alpha(1-\phi)^{2.5}}{45 A_{2}{ }^{2}}-\frac{\operatorname{Re}^{2} \alpha^{2}(1-\phi)^{5}}{90 A_{2}{ }^{2}}-\frac{H \operatorname{Re}^{2} \phi_{1}}{180 A_{2}}+\frac{H^{2} \operatorname{Re}^{2} \phi_{1}}{180 A_{2}}-\frac{\operatorname{Re}^{2} \alpha(1-\phi)^{2.5} \phi_{1}}{180 A_{2}}+\frac{H \operatorname{Re}^{2} \alpha(1-\phi)^{2.5} \phi_{1}}{180 A_{2}}$;

$m_{7}(t)=\frac{\operatorname{Re}^{2}}{252 A_{2}{ }^{2}}+\frac{\operatorname{Re}^{2} \alpha(1-\phi)^{2.5}}{252 A_{2}{ }^{2}}+\frac{\operatorname{Re}^{2} \phi_{1}}{1260 A_{2}}-\frac{H \operatorname{Re}^{2} \phi_{1}}{630 A_{2}}-\frac{\operatorname{Re}^{2} \alpha(1-\phi)^{2.5} \phi_{1}}{1260 A_{2}} ;$

$m_{8}(t)=-\frac{\mathrm{Re}^{2}}{2016 A_{2}^{2}}+\frac{\operatorname{Re}^{2} \phi_{1}}{10080 A_{2}} ;$

$n_{1}(t)=2 H-\frac{2 H^{4} \mathrm{Re}}{3 A_{2}}+\frac{4 H^{5} \mathrm{Re}}{15 A_{2}}-\frac{H^{2} \frac{\mathrm{d} H}{d t} \mathrm{Re}}{A_{2}}+\frac{5 H^{7} \mathrm{Re}^{2}}{18 A_{2}{ }^{2}}-\frac{97 H^{8} \mathrm{Re}^{2}}{420 A_{2}{ }^{2}}+\frac{79 H^{9} \mathrm{Re}^{2}}{1620 A_{2}{ }^{2}}+\frac{19 H^{5} \frac{\mathrm{d} H}{d t} \mathrm{Re}^{2}}{10 A_{2}{ }^{2}}-\frac{44 H^{6} \frac{\mathrm{dH}}{d t} \mathrm{Re}^{2}}{45 A_{2}{ }^{2}}+$ $\frac{H^{3}\left(\frac{\mathrm{d} H}{d t}\right)^{2} \operatorname{Re}^{2}}{A_{2}{ }^{2}}+\frac{5 H^{4} \frac{d^{2} H}{d t^{2}} \operatorname{Re}^{2}}{12 A_{2}{ }^{2}}-\frac{2 H^{4} \operatorname{Re} \alpha(1-\phi)^{2.5}}{3 A_{2}}+\frac{5 H^{7} \operatorname{Re}^{2} \alpha(1-\phi)^{2.5}}{9 A_{2}{ }^{2}}-\frac{97 H^{8} \operatorname{Re}^{2} \alpha(1-\phi)^{2.5}}{420 A_{2}{ }^{2}}+\frac{19 H^{5} \frac{\mathrm{d} H}{d t} \operatorname{Re}^{2} \alpha(1-\phi)^{2.5}}{10 A_{2}{ }^{2}}+$ $\frac{5 H^{7} \operatorname{Re}^{2} \alpha^{2}(1-\phi)^{5}}{18 A_{2}{ }^{2}}+\frac{137 H^{8} \operatorname{Re}^{2} \phi_{1}}{360 A_{2}}-\frac{1643 H^{9} \operatorname{Re}^{2} \phi_{1}}{22680 A_{2}}+\frac{47 H^{6} \frac{d H}{d t} \operatorname{Re}^{2} \phi_{1}}{180 A_{2}}-\frac{121 H^{7} \operatorname{Re}^{2} \alpha(1-\phi)^{2.5} \phi_{1}}{630 A_{2}}+\frac{239 H^{8} \operatorname{Re}^{2} \alpha(1-\phi)^{2.5} \phi_{1}}{360 A_{2}}$; $n_{2}(t)=-1$ 


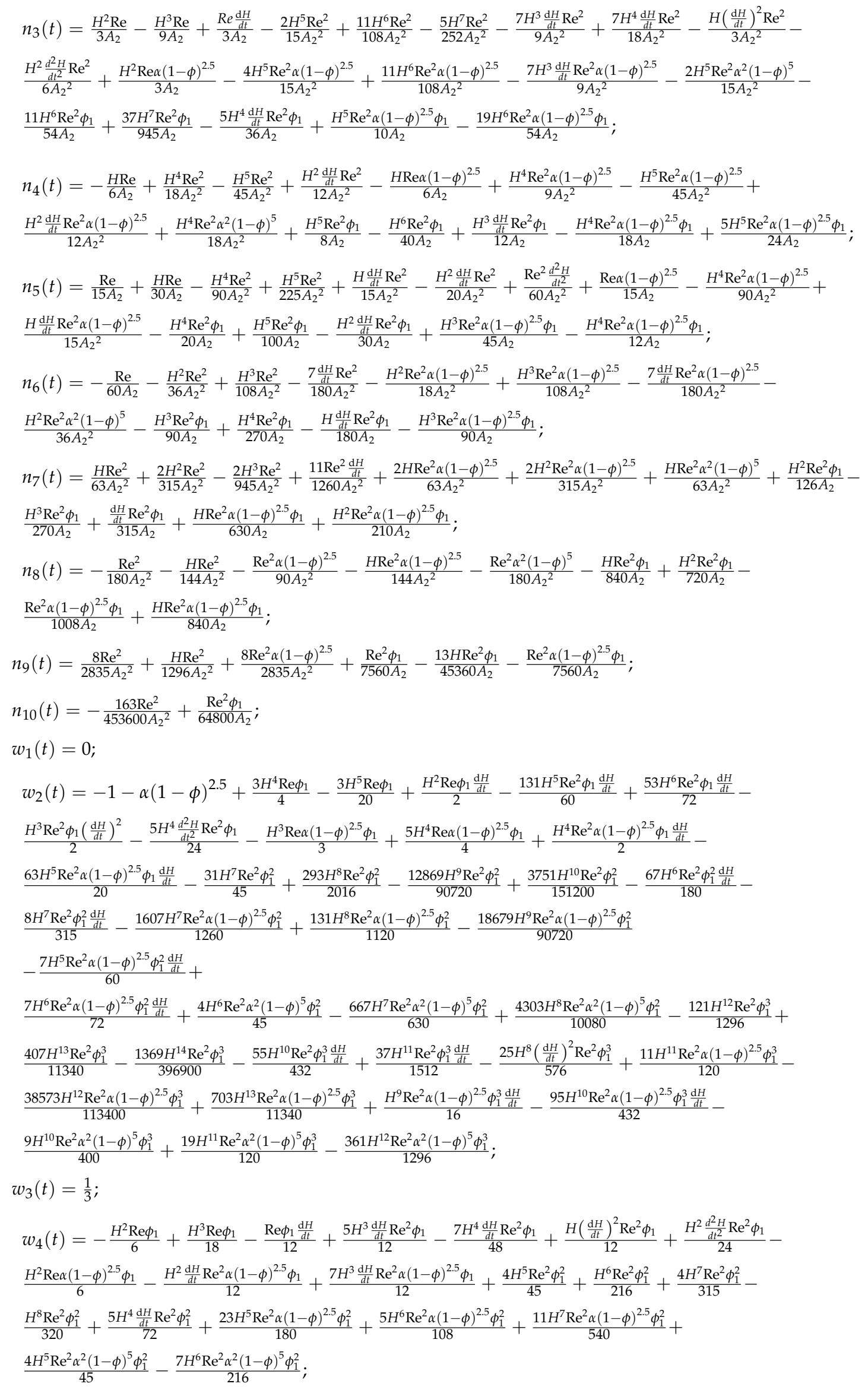


$w_{5}(t)=\frac{H \operatorname{Re} \phi_{1}}{30}-\frac{H^{2} \operatorname{Re} \phi_{1}}{30}+\frac{\operatorname{Re} \alpha(1-\phi)^{2.5} \phi_{1}}{30}-\frac{H \operatorname{Re} \alpha(1-\phi)^{2.5} \phi_{1}}{30}+\frac{H^{4} \operatorname{Re}^{2} \phi_{1}^{2}}{30}+\frac{H^{5} \operatorname{Re}^{2} \phi_{1}^{2}}{360}-\frac{7 H^{6} \operatorname{Re}^{2} \phi_{1}^{2}}{5400}+\frac{H^{3} \frac{\mathrm{d} H}{d t} \operatorname{Re}^{2} \phi_{1}^{2}}{60}+$ $\frac{29 H^{4} \operatorname{Re}^{2} \alpha(1-\phi)^{2.5} \phi_{1}^{2}}{360}+\frac{13 H^{5} \operatorname{Re}^{2} \alpha(1-\phi)^{2.5} \phi_{1}^{2}}{900}+\frac{H^{2} \frac{\mathrm{d} H}{d t} \operatorname{Re}^{2} \alpha(1-\phi)^{2.5} \phi_{1}^{2}}{60}-\frac{H^{3} \operatorname{Re}^{2} \alpha^{2}(1-\phi)^{5} \phi_{1}^{2}}{90}+\frac{3 H^{4} \operatorname{Re}^{2} \alpha^{2}(1-\phi)^{5} \phi_{1}^{2}}{40} ;$ $w_{6}(t)=-\frac{\operatorname{Re} \phi_{1}}{180}+\frac{H \operatorname{Re} \phi_{1}}{90}-\frac{H \frac{d H}{d t} \operatorname{Re}^{2} \phi_{1}}{45}+\frac{H^{2} \frac{d H}{d t} \operatorname{Re}^{2} \phi_{1}}{90}-\frac{\frac{d^{2} H}{d t^{2}} \operatorname{Re}^{2} \phi_{1}}{360}+\frac{\operatorname{Re} \alpha(1-\phi)^{2.5} \phi_{1}}{180}-\frac{H \frac{d H}{d t} \operatorname{Re}^{2} \alpha(1-\phi)^{2.5} \phi_{1}}{45}-$ $\frac{H^{4} \operatorname{Re}^{2} \phi_{1}^{2}}{48}+\frac{H^{5} \operatorname{Re}^{2} \phi_{1}^{2}}{240}-\frac{H^{2} \frac{\mathrm{d} H}{d t} \operatorname{Re}^{2} \phi_{1}^{2}}{72}+\frac{H^{3} \operatorname{Re}^{2} \alpha(1-\phi)^{2.5} \phi_{1}^{2}}{108}-\frac{17 H^{4} \operatorname{Re}^{2} \alpha(1-\phi)^{2.5} \phi_{1}^{2}}{360}+\frac{H^{5} \operatorname{Re}^{2} \alpha(1-\phi)^{2.5} \phi_{1}^{2}}{400}-$ $\frac{H^{2} \frac{\mathrm{d} H}{d t} \operatorname{Re}^{2} \alpha(1-\phi)^{2.5} \phi_{1}^{2}}{120}+\frac{H^{3} \operatorname{Re}^{2} \alpha^{2}(1-\phi)^{5} \phi_{1}^{2}}{180}-\frac{H^{4} \operatorname{Re}^{2} \alpha^{2}(1-\phi)^{5} \phi_{1}^{2}}{48}+\frac{3 H^{8} \operatorname{Re}^{2} \phi_{1}^{3}}{320}-\frac{3 H^{9} \operatorname{Re}^{2} \phi_{1}^{3}}{800}+\frac{3 H^{10} \operatorname{Re}^{2} \phi_{1}^{3}}{8000}+$ $\frac{H^{6} \frac{\mathrm{d} H}{d t} \operatorname{Re}^{2} \phi_{1}^{3}}{80}-\frac{H^{7} \frac{\mathrm{d} H}{d t} \operatorname{Re}^{2} \phi_{1}^{3}}{400}+\frac{H^{4}\left(\frac{\mathrm{d} H}{d t}\right)^{2} \operatorname{Re}^{2} \phi_{1}^{3}}{240}-\frac{H^{7} \operatorname{Re}^{2} \alpha(1-\phi)^{2.5} \phi_{1}^{3}}{120}+\frac{79 H^{8} \operatorname{Re}^{2} \alpha(1-\phi)^{2.5} \phi_{1}^{3}}{2400}-\frac{H^{9} \operatorname{Re}^{2} \alpha(1-\phi)^{2.5} \phi_{1}^{3}}{160}-$ $\frac{H^{5} \frac{\mathrm{d} H}{d t} \operatorname{Re}^{2} \alpha(1-\phi)^{2.5} \phi_{1}^{3}}{180}+\frac{H^{6} \frac{\mathrm{d} H}{d t} \operatorname{Re}^{2} \alpha(1-\phi)^{2.5} \phi_{1}^{3}}{48}+\frac{H^{6} \operatorname{Re}^{2} \alpha^{2}(1-\phi)^{5} \phi_{1}^{3}}{540}-\frac{H^{7} \operatorname{Re}^{2} \alpha^{2}(1-\phi)^{5} \phi_{1}^{3}}{72}+\frac{5 H^{8} \operatorname{Re}^{2} \alpha^{2}(1-\phi)^{5} \phi_{1}^{3}}{192} ;$ $w_{7}(t)=-\frac{\operatorname{Re} \phi_{1}}{1260}+\frac{\operatorname{Re}^{2} \phi_{1} \frac{d H}{d t}}{1260}-\frac{H \operatorname{Re}^{2} \phi_{1} \frac{d H}{d t}}{630}-\frac{\operatorname{Re}^{2} \alpha(1-\phi)^{2.5} \phi_{1} \frac{d H}{d t}}{1260}-\frac{H^{2} \operatorname{Re}^{2} \phi_{1}^{2}}{105}-\frac{H^{3} \operatorname{Re}^{2} \phi_{1}^{2}}{630}+\frac{H^{4} \operatorname{Re}^{2} \phi_{1}^{2}}{252}-\frac{H^{5} \operatorname{Re}^{2} \phi_{1}^{2}}{2100}-$ $\frac{H \frac{\mathrm{d} H}{d t} \operatorname{Re}^{2} \phi_{1}^{2}}{420}+\frac{H^{2} \frac{\mathrm{d} H}{d t} \operatorname{Re}^{2} \phi_{1}^{2}}{630}-\frac{H^{2} \operatorname{Re}^{2} \alpha(1-\phi)^{2.5} \phi_{1}^{2}}{42}-\frac{H^{3} \operatorname{Re}^{2} \alpha(1-\phi)^{2.5} \phi_{1}^{2}}{945}+\frac{H^{4} \operatorname{Re}^{2} \alpha(1-\phi)^{2.5} \phi_{1}^{2}}{252}-\frac{\frac{\mathrm{d} H}{d t} \operatorname{Re}^{2} \alpha(1-\phi)^{2.5} \phi_{1}^{2}}{420}-$ $\frac{H^{2} \operatorname{Re}^{2} \alpha^{2}(1-\phi)^{5} \phi_{1}^{2}}{70}$;

$w_{8}(t)=\frac{\operatorname{Re}^{2} \phi_{1} \frac{d H}{d t}}{5040}+\frac{2 H^{2} \operatorname{Re}^{2} \phi_{1}^{2}}{315}-\frac{H^{3} \operatorname{Re}^{2} \phi_{1}^{2}}{378}+\frac{17 \frac{d H}{d t} \operatorname{Re}^{2} \phi_{1}^{2}}{10080}+\frac{H \operatorname{Re}^{2} \alpha(1-\phi)^{2.5} \phi_{1}^{2}}{630}+\frac{11 H^{2} \operatorname{Re}^{2} \alpha(1-\phi)^{2.5} \phi_{1}^{2}}{1680}-$ $\frac{13 H^{3} \operatorname{Re}^{2} \alpha(1-\phi)^{2.5} \phi_{1}^{2}}{15120}+\frac{\frac{\mathrm{dH}}{d t} \operatorname{Re}^{2} \alpha(1-\phi)^{2.5} \phi_{1}^{2}}{1008}+\frac{\operatorname{Re}^{2} \alpha^{2}(1-\phi)^{5} \phi_{1}^{2}}{1260}-\frac{H \operatorname{Re}^{2} \alpha^{2}(1-\phi)^{5} \phi_{1}^{2}}{1260}+\frac{13 H^{2} \operatorname{Re}^{2} \alpha^{2}(1-\phi)^{5} \phi_{1}^{2}}{5040}-\frac{H^{6} \operatorname{Re}^{2} \phi_{1}^{3}}{448}+$ $\frac{H^{7} \operatorname{Re}^{2} \phi_{1}^{3}}{840}-\frac{H^{8} \operatorname{Re}^{2} \phi_{1}^{3}}{6720}-\frac{H^{4} \frac{\mathrm{d} H}{d t} \operatorname{Re}^{2} \phi_{1}^{3}}{384}+\frac{29 H^{5} \frac{\mathrm{d} H}{d t} \operatorname{Re}^{2} \phi_{1}^{3}}{40320}-\frac{H^{2}\left(\frac{\mathrm{d} H}{d t}\right)^{2} \operatorname{Re}^{2} \phi_{1}^{3}}{1344}+\frac{H^{5} \operatorname{Re}^{2} \alpha(1-\phi)^{2.5} \phi_{1}^{3}}{1008}-\frac{19 H^{6} \operatorname{Re}^{2} \alpha(1-\phi)^{2.5} \phi_{1}^{3}}{3024}+$ $\frac{17 H^{7} \operatorname{Re}^{2} \alpha(1-\phi)^{2.5} \phi_{1}^{3}}{10080}+\frac{H^{3} \frac{\mathrm{d} H}{d t} \operatorname{Re}^{2} \alpha(1-\phi)^{2.5} \phi_{1}^{3}}{2016}-\frac{3 H^{4} \frac{\mathrm{d} H}{d t} \operatorname{Re}^{2} \alpha(1-\phi)^{2.5} \phi_{1}^{3}}{896}+\frac{H^{5} \operatorname{Re}^{2} \alpha^{2}(1-\phi)^{5} \phi_{1}^{3}}{1008}-\frac{5 H^{6} \operatorname{Re}^{2} \alpha^{2}(1-\phi)^{5} \phi_{1}^{3}}{1344} ;$ $w_{9}(t)=\frac{\operatorname{Re}^{2} \phi_{1}^{2}}{1620}-\frac{31 H \operatorname{Re}^{2} \phi_{1}^{2}}{45360}+\frac{H^{2} \operatorname{Re}^{2} \phi_{1}^{2}}{3780}+\frac{H^{3} \operatorname{Re}^{2} \phi_{1}^{2}}{5670}-\frac{\frac{\mathrm{d} H}{d t} \operatorname{Re}^{2} \phi_{1}^{2}}{4536}+\frac{5 \operatorname{Re}^{2} \alpha(1-\phi)^{2.5} \phi_{1}^{2}}{9072}+\frac{13 H \operatorname{Re}^{2} \alpha(1-\phi)^{2.5} \phi_{1}^{2}}{22680}-$ $\frac{H^{2} \operatorname{Re}^{2} \alpha(1-\phi)^{2.5} \phi_{1}^{2}}{5040}+\frac{\operatorname{Re}^{2} \alpha^{2}(1-\phi)^{5} \phi_{1}^{2}}{2520}+\frac{H \operatorname{Re}^{2} \alpha^{2}(1-\phi)^{5} \phi_{1}^{2}}{3024}+\frac{H^{5} \operatorname{Re}^{2} \phi_{1}^{3}}{2880}-\frac{H^{6} \operatorname{Re}^{2} \phi_{1}^{3}}{2400}+\frac{H^{7} \operatorname{Re}^{2} \phi_{1}^{3}}{14400}+\frac{H^{3} \frac{\mathrm{d} H}{d t} \operatorname{Re}^{2} \phi_{1}^{3}}{4320}-$ $\frac{H^{4} \frac{\mathrm{d} H}{d t} \operatorname{Re}^{2} \phi_{1}^{3}}{4320}+\frac{H^{4} \operatorname{Re}^{2} \alpha(1-\phi)^{2.5} \phi_{1}^{3}}{5184}+\frac{41 H^{5} \operatorname{Re}^{2} \alpha(1-\phi)^{2.5} \phi_{1}^{3}}{129600}-\frac{11 H^{6} \operatorname{Re}^{2} \alpha(1-\phi)^{2.5} \phi_{1}^{3}}{21600}+\frac{H^{2} \frac{\mathrm{d} H}{d t} \operatorname{Re}^{2} \alpha(1-\phi)^{2.5} \phi_{1}^{3}}{4320}-$ $\frac{H^{3} \frac{\mathrm{d} H}{d t} \operatorname{Re}^{2} \alpha(1-\phi)^{2.5} \phi_{1}^{3}}{4320}-\frac{H^{3} \operatorname{Re}^{2} \alpha^{2}(1-\phi)^{5} \phi_{1}^{3}}{6480}+\frac{19 H^{4} \operatorname{Re}^{2} \alpha^{2}(1-\phi)^{5} \phi_{1}^{3}}{25920}-\frac{H^{5} \operatorname{Re}^{2} \alpha^{2}(1-\phi)^{5} \phi_{1}^{3}}{1728} ;$ $w_{10}(t)=-\frac{83 \operatorname{Re}^{2} \phi_{1}^{2}}{453600}-\frac{H \operatorname{Re}^{2} \phi_{1}^{2}}{10080}-\frac{H^{2} \operatorname{Re}^{2} \phi_{1}^{2}}{12960}-\frac{127 \operatorname{Re}^{2} \alpha(1-\phi)^{2.5} \phi_{1}^{2}}{453600}-\frac{11 H \operatorname{Re}^{2} \alpha(1-\phi)^{2.5} \phi_{1}^{2}}{64800}-\frac{41 \operatorname{Re}^{2} \alpha^{2}(1-\phi)^{5} \phi_{1}^{2}}{453600}+$ $\frac{7 H^{4} \operatorname{Re}^{2} \phi_{1}^{3}}{64800}-\frac{H^{5} \operatorname{Re}^{2} \phi_{1}^{3}}{972000}-\frac{H^{6} \operatorname{Re}^{2} \phi_{1}^{3}}{729000}+\frac{H^{2} \frac{d H}{d t} \operatorname{Re}^{2} \phi_{1}^{3}}{8100}+\frac{H^{3} \frac{d H}{d t} \operatorname{Re}^{2} \phi_{1}^{3}}{97200}+\frac{\left(\frac{d H}{d t}\right)^{2} \operatorname{Re}^{2} \phi_{1}^{3}}{25920}+\frac{H^{3} \operatorname{Re}^{2} \alpha(1-\phi)^{2.5} \phi_{1}^{3}}{48600}+$ $\frac{23 H^{4} \operatorname{Re}^{2} \alpha(1-\phi)^{2.5} \phi_{1}^{3}}{97200}+\frac{41 H^{5} \operatorname{Re}^{2} \alpha(1-\phi)^{2.5} \phi_{1}^{3}}{972000}+\frac{H^{2} \frac{\mathrm{dH}}{d t} \operatorname{Re}^{2} \alpha(1-\phi)^{2.5} \phi_{1}^{3}}{5400}-\frac{H^{3} \operatorname{Re}^{2} \alpha^{2}(1-\phi)^{5} \phi_{1}^{3}}{48600}+\frac{H^{4} \operatorname{Re}^{2} \alpha^{2}(1-\phi)^{5} \phi_{1}^{3}}{4320} ;$ $w_{11}(t)=\frac{41 \operatorname{Re}^{2} \phi_{1}^{2}}{1247400}+\frac{H \operatorname{Re}^{2} \phi_{1}^{2}}{44550}+\frac{\operatorname{Re}^{2} \alpha(1-\phi)^{2.5} \phi_{1}^{2}}{32400}-\frac{H^{3} \operatorname{Re}^{2} \phi_{1}^{3}}{19800}+\frac{103 H^{4} \operatorname{Re}^{2} \phi_{1}^{3}}{1663200}-\frac{131 H^{5} \operatorname{Re}^{2} \phi_{1}^{3}}{8316000}-\frac{H \frac{\mathrm{dH}}{d t} \operatorname{Re}^{2} \phi_{1}^{3}}{39600}+$ $\frac{H^{2} \frac{\mathrm{d} H}{d t} \operatorname{Re}^{2} \phi_{1}^{3}}{46200}-\frac{H^{2} \operatorname{Re}^{2} \alpha(1-\phi)^{2.5} \phi_{1}^{3}}{19800}+\frac{H^{3} \operatorname{Re}^{2} \alpha(1-\phi)^{2.5} \phi_{1}^{3}}{51975}+\frac{41 H^{4} \operatorname{Re}^{2} \alpha(1-\phi)^{2.5} \phi_{1}^{3}}{1663200}-\frac{\frac{\mathrm{d} H}{d t} \operatorname{Re}^{2} \alpha(1-\phi)^{2.5} \phi_{1}^{3}}{39600}+$ $\frac{H \frac{\mathrm{d} H}{d t} \operatorname{Re}^{2} \alpha(1-\phi)^{2.5} \phi_{1}^{3}}{39600}-\frac{H^{2} \operatorname{Re}^{2} \alpha^{2}(1-\phi)^{5} \phi_{1}^{3}}{19800}+\frac{H^{3} \operatorname{Re}^{2} \alpha^{2}(1-\phi)^{5} \phi_{1}^{3}}{19800} ;$

$w_{12}(t)=-\frac{\operatorname{Re}^{2} \phi_{1}^{2}}{388800}+\frac{H^{2} \operatorname{Re}^{2} \phi_{1}^{3}}{89100}-\frac{53 H^{3} \operatorname{Re}^{2} \phi_{1}^{3}}{2138400}+\frac{19 H^{4} \operatorname{Re}^{2} \phi_{1}^{3}}{2138400}+\frac{\frac{\mathrm{d} H}{d t} \operatorname{Re}^{2} \phi_{1}^{3}}{285120}-\frac{H \frac{\mathrm{d} H}{d t} \operatorname{Re}^{2} \phi_{1}^{3}}{142560}+\frac{H \operatorname{Re}^{2} \alpha(1-\phi)^{2.5} \phi_{1}^{3}}{118800}-$ $\frac{H^{2} \operatorname{Re}^{2} \alpha(1-\phi)^{2.5} \phi_{1}^{3}}{59400}-\frac{7 H^{3} \operatorname{Re}^{2} \alpha(1-\phi)^{2.5} \phi_{1}^{3}}{2138400}-\frac{\frac{\mathrm{d} H}{d t} \operatorname{Re}^{2} \alpha(1-\phi)^{2.5} \phi_{1}^{3}}{285120}+\frac{\operatorname{Re}^{2} \alpha^{2}(1-\phi)^{5} \phi_{1}^{3}}{237600}-\frac{H \operatorname{Re}^{2} \alpha^{2}(1-\phi)^{5} \phi_{1}^{3}}{118800}-$ $\frac{H^{2} \operatorname{Re}^{2} \alpha^{2}(1-\phi)^{5} \phi_{1}^{3}}{356400}$

$w_{13}(t)=-\frac{H \operatorname{Re}^{2} \phi_{1}^{3}}{842400}+\frac{H^{2} \operatorname{Re}^{2} \phi_{1}^{3}}{226800}-\frac{47 H^{3} \operatorname{Re}^{2} \phi_{1}^{3}}{17690400}+\frac{\frac{\mathrm{d} H}{d t} \operatorname{Re}^{2} \phi_{1}^{3}}{2358720}-\frac{\operatorname{Re}^{2} \alpha(1-\phi)^{2.5} \phi_{1}^{3}}{842400}+\frac{H \operatorname{Re}^{2} \alpha(1-\phi)^{2.5} \phi_{1}^{3}}{210600}-$ $\frac{H^{2} \operatorname{Re}^{2} \alpha(1-\phi)^{2.5} \phi_{1}^{3}}{368550}+\frac{\operatorname{Re}^{2} \alpha^{2}(1-\phi)^{5} \phi_{1}^{3}}{842400}-\frac{H \operatorname{Re}^{2} \alpha^{2}(1-\phi)^{5} \phi_{1}^{3}}{842400} ;$

$w_{14}(t)=\frac{\operatorname{Re}^{2} \phi_{1}^{3}}{11793600}-\frac{H \operatorname{Re}^{2} \phi_{1}^{3}}{2063880}+\frac{H^{2} \operatorname{Re}^{2} \phi_{1}^{3}}{2063880}-\frac{\operatorname{Re}^{2} \alpha(1-\phi)^{2.5} \phi_{1}^{3}}{3175200}+\frac{H \operatorname{Re}^{2} \alpha(1-\phi)^{2.5} \phi_{1}^{3}}{2063880}+\frac{\operatorname{Re}^{2} \alpha^{2}(1-\phi)^{5} \phi_{1}^{3}}{11793600} ;$

$w_{15}(t)=\frac{\operatorname{Re}^{2} \phi_{1}^{3}}{47628000}-\frac{H \operatorname{Re}^{2} \phi_{1}^{3}}{23814000}-\frac{\operatorname{Re}^{2} \alpha(1-\phi)^{2.5} \phi_{1}^{3}}{47628000} ;$ 
$w_{16}(t)=\frac{\operatorname{Re}^{2} \phi_{1}^{3}}{762048000} ;$

Similarly, some constants have also been enlisted as

$A_{1}=\frac{k_{n f}}{k_{f}} ;$

$A_{2}=\frac{A_{1}}{\operatorname{Pr} \phi_{2}}$

$\phi_{1}=\left(1.013+0.092 \phi-0.015 \phi^{2}\right)\left[1-\phi\left(1+\frac{\rho_{p}}{\rho_{f}}\right)\right] ;$

$\phi_{2}=(1-\phi)-\phi \frac{\left(\rho C_{p}\right)_{p}}{\left(\rho C_{p}\right)_{f}}$.

\section{References}

1. Acrivos, A.; Shah, M.J.; Petersen, E.E. On the flow of a Non-Newtonian liquid on a rotating disk. J. Appl. Phys. 1960, 31, 963-968. [CrossRef]

2. Dandapat, B.S.; Maity, S.; Kitamura, A. Liquid film flow due to an unsteady stretching sheet. Int. J. Non-Linear Mech. 2008, 43, 880-886. [CrossRef]

3. Mcintryre, A.; Brush, L.N. Spin-coating of vertically stratified thin liquid films. J. Fluid Mech. 2010, 647, $265-285$. [CrossRef]

4. Choi, S.U.S.; Eastman, J.A. Enhancing thermal conductivity of fluids with nanoparticles. ASME Publ. Fed 1995, 231, 99-106.

5. Buongiorno, J.; Hu, W. Nanofluid coolants for advanced nuclear power plants. In Proceedings of the ICAPP, Seoul, Korea, 15-19 May 2005; Volume 5, pp. 15-19.

6. Buongiorno, J. Convective transport in nanofluids. J. Heat Transf. 2006, 128, 240-250. [CrossRef]

7. Xu, H.; Fan, T.; Pop, I. Analysis of mixed convection flow of a nanofluid in a vertical channel with the Buongiorno mathematical model. Int. Commun. Heat Mass Transf. 2013, 44, 15-22. [CrossRef]

8. Sheikholeslami, M.; Bhatti, M.M. Active method for nanofluid heat transfer enhancement by means of EHD. Int. J. Heat Mass Transf. 2017, 109, 115-122. [CrossRef]

9. Hassan, M.; Zeeshan, A.; Majeed, A.; Ellahi, R. Particle shape effects on ferro fluid flow and heat transfer under influence of low oscillating magnetic field. J. Magn. Magn. Mater. 2017, 443, 36-44. [CrossRef]

10. Bhatti, M.M.; Abbas, T.; Rashidi, M.M.; Ali, M.E.; Yang, Z. Entropy generation on MHD Eyring-Powell nanofluid through a permeable stretching surface. Entropy 2016, 18, 224. [CrossRef]

11. Alamri, S.Z.; Ellahi, R.; Shehzad, N.; Zeeshan, A. Convective radiative plane Poiseuille flow of nanofluid through porous medium with slip: An application of Stefan blowing. J. Mol. Liq. 2019, 273, $292-304$. [CrossRef]

12. Majeed, A.; Zeeshan, A.; Alamri, S.Z.; Ellahi, R. Heat transfer analysis in ferromagnetic viscoelastic fluid flow over a stretching sheet with suction. Neural Comput. Appl. 2018, 30, 1947-1955. [CrossRef]

13. Tripathi, D.; Bhushan, S.; Anwar Beg, O. Transverse magnetic field driven modification in unsteady peristaltic transport with electrical double layer effects. Colloids Surf. A Physicochem. Eng. Asp. 2016, 506, 32-39. [CrossRef]

14. Khan, W.G.; Idrees, T.; Islam, M.; Khan, S.; Dennis, L.C. Thin film Williamson nanofluid flow with varying viscosity and thermal conductivity on a time-dependent stretching sheet. Appl. Sci. 2016, 6, 334. [CrossRef]

15. Ellahi, R. Special issue on recent developments of nanofluids. Appl. Sci. 2018, 8, 192. [CrossRef]

16. Tripathi, D.; Beg, O.A. A numerical study of the oscillating peristaltic flow of generalized Maxwell viscoelastic fluids through a porous medium. Trans. Porous Med. 2012, 95, 337-348. [CrossRef]

17. Bhatti, M.M.; Rashidi, M.M. Effects of thermo-diffusion and thermal radiation on Williamson nanofluid over a porous shrinking/stretching sheet. J. Mol. Liq. 2016, 221, 567-573. [CrossRef]

18. Marin, M. An approach of a heat-flux dependent theory for micropolar porous media. Meccanica 2016, 51, 127-1133. [CrossRef]

19. Hameed, M.; Ellahi, R. Thin film flow of non-Newtonian MHD fluid on a vertically moving belt. Int. J. Numer. Method Fluids 2011, 66, 1409-1419. [CrossRef]

20. Abbasbandy, S.; Hayat, T.; Mahomed, F.M.; Ellahi, R. On comparison of exact and series solutions for thin film flow of a third grade fluid. Int. J. Numer. Method Fluids 2009, 61, 987-994. [CrossRef] 
21. Hayat, T.; Ellahi, R.; Mahomed, F.M. Exact solutions for thin film flow of a third grade fluid down an inclined plane. Chaos Solitons Fractals 2008, 38, 1336-1341. [CrossRef]

22. Hayat, T.; Ellahi, R.; Mahomed, F.M. Exact solution of a thin film flow of an Oldroyd 6-constant fluid over a moving belt, Commun. Nonlinear Sci. Numer. Simul. 2009, 14, 133-139. [CrossRef]

23. Reyes, M.E.A.; Delgado, G.T.; Pérez, R.C.; Marín, J.M.; Ángel, O.Z. Optimization of the photocatalytic activity of $\mathrm{CdO}+\mathrm{CdTiO}_{3}$ coupled oxide thin films obtained by sol-gel technique. J. Photochem. Photobiol. A Chem. 2012, 228, 22-27. [CrossRef]

24. Xu, H.; Pop, I.; You, X.C. Flow and heat transfer in a nano-liquid film over an unsteady stretching surface. Int. J. Heat Mass Transf. 2013, 60, 646-652. [CrossRef]

25. Sheikholeslami, M.; Ashorynejad, H.R.; Ganji, D.D.; Yıldırım, A. Homotopy perturbation method for three-dimensional problem of condensation film on inclined rotating disk. Sci. Iran. 2012, 19, 437-442. [CrossRef]

26. Chen, X.; Dai, W.; Wu, T.; Luo, W.; Yang, J.; Jiang, W.; Wang, L. Thin film thermoelectric materials: Classification, characterization and potential for wearable applications. Coatings 2018, 8, 244. [CrossRef]

27. Osiac, $\mathrm{M}$. The electrical and structural properties of nitrogen $\mathrm{Ge}_{1} \mathrm{Sb}_{2} \mathrm{Te}_{4}$ thin film. Coatings 2018, 8, 117. [CrossRef]

28. Radwan, A.B.; Abdullah, A.M.; Mohamed, A.M.A.; Al-Maadeed, M.A. New electrospun polystyrene $/ \mathrm{Al}_{2} \mathrm{O}_{3}$ nanocomposite superhydrophobic coatings; synthesis, characterization, and application. Coatings 2018, 8, 65. [CrossRef]

29. Yamamuro, H.; Hatsuta, N.; Wachi, M.; Takei, Y.; Takashiri, M. Combination of electrodeposition and transfer processes for flexible thin-film thermoelectric generators. Coatings 2018, 8, 22. [CrossRef]

30. Sheikholeslami, M.; Ellahi, R. Electrohydrodynamic nanofluid hydrothermal treatment in an enclosure with sinusoidal upper wall. Appl. Sci. 2015, 5, 294-306. [CrossRef]

31. Sheikholeslami, M.; Zia, Q.M.; Ellahi, R. Influence of induced magnetic field on free convection of nanofluid considering Koo-Kleinstreuer-Li (KKL) correlation. Appl. Sci. 2016, 6, 324. [CrossRef]

32. Rashidi, S.; Esfahani, J.A.; Ellahi, R. Convective heat transfer and particle motion in an obstructed duct with two side by side obstacles by means of DPM model. Appl. Sci. 2017, 7, 431. [CrossRef]

33. Zeeshan, A.; Ijaz, N.; Abbas, T.; Ellahi, R. The sustainable characteristic of Bio-bi-phase flow of peristaltic transport of MHD Jeffery fluid in human body. Sustainability 2018, 10, 2671. [CrossRef]

34. Hussain, F.; Ellahi, R.; Zeeshan, A. Mathematical models of electro magnetohydrodynamic multiphase flows synthesis with nanosized hafnium particles. Appl. Sci. 2018, 8, 275. [CrossRef]

35. Haq, R.U.; Soomro, F.A.; Hammouch, Z.; Rehman, S. Heat exchange within the partially heated C-shape cavity filled with the water based SWCNTs. Int. J. Heat Mass Transf. 2018, 127, 506-514. [CrossRef]

36. Usman, M.; Hamid, M.; Zubair, T.; Haq, R.U.; Wang, W. Cu- $\mathrm{Al}_{2} \mathrm{O}_{3}$ /water hybrid nanofluid through a permeable surface in the presence of nonlinear radiation and variable thermal conductivity via LSM. Int. J. Heat Mass Transf. 2018, 126, 1347-1356. [CrossRef]

37. Haq, R.U.; Aman, S. Water functionalized $\mathrm{CuO}$ nanoparticles filled in a partially heated trapezoidal cavity with inner heated obstacle: FEM approach. Int. J. Heat Mass Transf. 2019, 128, 401-417. [CrossRef]

38. Khan, Z.; Shah, R.A.; Islam, S.; Jan, H.; Jan, B.; Rasheed, H. MHD flow and heat transfer analysis in the wirecoating process using elastic-viscous. Coatings 2017, 7, 15. [CrossRef]

39. Naghdi, S.; Rhee, K.Y.; Hui, D.; Paark, S.J. A review of conductive metal nanomaterials as conductive, Transparent, and flexible coatings, thin films, and conductive fillers: Different deposition methods and applications. Coatings 2018, 8, 278. [CrossRef]

40. Maity, S. Thermocapillary flow of thin $\mathrm{Cu}$-water nanoliquids film during spin coating process. Int. Nano Lett. 2017, 7, 9-23. [CrossRef]

41. Khanafer, K.; Vafai, K. A critical synthesis of thermophysical characteristics of nanofluids. Int. J. Heat Mass Transf. 2011, 54, 4410-4428. [CrossRef]

42. Duangthongsuk, W.; Wongwises, S. Effect of thermophysical properties models on the predicting of the convective heat transfer coefficient for low concentration nanofluid. Int. Commun. Heat Mass Trnasf. 2008, 35, 1320-1326. [CrossRef]

43. Peyghambarzadeh, S.M.; Hashemabadi, S.H.; Hoseini, S.M.; Jamnani, M.S. Experimental study of heat transfer enhancement using water/ethylene glycol based nanofluids as a new coolant for car radiators. Int. Commun. Heat Mass Transf. 2011, 38, 1283-1290. [CrossRef] 
44. Darvanjooghi, M.H.K.; Esfahany, M.N. Experimental investigation of the effect of nanoparticle size on thermal conductivity of in-situ prepared silica-ethanol nanofluid. Int. Commun. Heat Mass Transf. 2016, 77, 148-154. [CrossRef]

45. Pineda, I.T.; Lee, J.W.; Jung, I.; Kang, Y.T. $\mathrm{CO}_{2}$ absorption enhancement by methanol-based $\mathrm{Al}_{2} \mathrm{O}_{3}$ and $\mathrm{SiO}_{2}$ nanofluids in a tray column absorber. Int. J. Refrig. 2012, 35, 1402-1409. [CrossRef]

46. Zeeshan, A.; Ellahi, R.; Hassan, M. Magnetohydrodynamic flow of water/ethylene glycol based nanofluids with natural convection through a porous medium. Eur. Phys. J. Plus 2014, 129, 261. [CrossRef]

47. Kang, S.W.; Wei, W.C.; Tsai, S.H.; Yang, S.Y. Experimental investigation of silver nano-fluid on heat pipe thermal performance. Appl. Therm. Eng. 2006, 26, 2377-2382. [CrossRef]

48. Kumar, B.R.; Basheer, N.S.; Jacob, S.; Kurian, A.; George, S.D. Thermal-lens probing of the enhanced thermal diffusivity of gold nanofluid-ethylene glycol mixture. J. Therm. Anal. Calorim. 2015, 119, 453-460. [CrossRef]

(C) 2018 by the authors. Licensee MDPI, Basel, Switzerland. This article is an open access article distributed under the terms and conditions of the Creative Commons Attribution (CC BY) license (http:/ / creativecommons.org/licenses/by/4.0/). 